\title{
Climate space, bioclimatic envelopes and coexistence methods for the reconstruction of past climates: a method using Australian beetles and significance for Quaternary reconstruction
}

\author{
Nick Porch* \\ Archaeology and Natural History, ANU College of Asia and the Pacific, The Australian National University, Canberra, ACT 0200, Australia
}

\section{A R T I C L E I N F O}

Article history:

Received 23 November 2007

Received in revised form

21 October 2009

Accepted 21 October 2009

\begin{abstract}
A B S T R A C T
If Quaternary palaeoclimatic reconstructions are to be adequately contextualised, it is vital that the nature of modern datasets and the limitations this places on interpreting Quaternary climates are made explicit - such issues are too infrequently considered. This paper describes a coexistence method for the reconstruction of past temperature and precipitation parameters in Australia, using fossil beetles. It presents the context for Quaternary palaeoclimatic reconstruction in terms of climate space, bioclimatic envelope data derived from modern beetle distributions, and the palaeoclimatic limitations of bioclimatic envelope-based reconstructions. Tests in modern climate space, using bioclimatic envelope data for 734 beetle taxa and 54 site-based assemblages from across the continent, indicate that modern seasonal, especially summer, temperatures and precipitation are accurately and, in the case of temperature, precisely reconstructed. The limitations of modern climate space, especially in terms of the limited seasonal variation in thermal regimes and subsequent lack of cold winters in the Australian region, renders winter predictions potentially unreliable when applied to the Quaternary record.
\end{abstract}

Crown Copyright (C) 2009 Published by Elsevier Ltd. All rights reserved.

\section{Introduction}

The reconstruction of past climates is a fundamental concern of Quaternary research. The ability to reconstruct the rate and magnitude of climate variability in terms of thermal and moisture regimes allows a range of key questions regarding climate dynamics, environmental and human history to be addressed. In Australia, as elsewhere, approaches to palaeoclimatic reconstruction have relied heavily on pollen analysis (Harle et al., 2004; Cook and van der Kaars, 2006; Turney et al., 2006b; Kershaw and van der Kaars, 2007; Williams et al., 2009). Pollen-based methods have many advantages for reconstructing past vegetation history, mainly the potential for temporal continuity at moderate to high time resolutions and small sample size requirements. They can be problematic, however, for quantification of past climates especially during glacial periods- principally because of major differences in the nature of glacial assemblages relative to those encountered in the recent record and at present (Jackson and Williams, 2004; Nielsen and Odgaard, 2004).

These issues are amplified in southeastern Australia where pollen assemblages are dominated by a small number of highly

\footnotetext{
* Tel.: +61 26125 5975; fax: +6126125 4917

E-mail address: nicholas.porch@anu.edu.au
}

speciose pollen types and few indicator taxa are present. Further, the relative paucity of ideal pollen sites means that calibration datasets are derived from a wide variety of contexts ranging from swamps and fens to freshwater and playa lakes making meaningful comparison of pollen assemblages difficult, if not impossible. The probable physiological effects of lowered $\mathrm{CO}_{2}$ on plant growth (Hesse et al., 2003), micro-topographic influences on bioclimates, and the lack of good analogues for Australian glacial assemblages (Kershaw and Bulman, 1996), imply that assemblage-based reconstructions using pollen data need to be interpreted cautiously. The continuing use of qualitative descriptive terms like 'warm', 'wetter', 'dry', 'colder' in reference to the climatic significance of pollen assemblage data in Australia (e.g. Turney et al., 2006a,b; Kershaw and van der Kaars, 2007; Williams et al., 2009), and frequent use of relative rather than absolute estimates of past changes in temperature and precipitation (see Williams et al., 2009 for a recent example), illustrates the qualified nature and continued ambiguity regarding the climatic significance of past pollen assemblages in the region. In the Australian context, the last several decades have seen the development and application of a range of methods for reconstruction of past climates from Quaternary data. These techniques, borrowed, sometimes uncritically, from the Northern Hemisphere, have been based largely on analysis of the extensive pollen record assembled over the last 40 years (Kershaw and Nix, 1988; Kershaw 
et al., 1994, 2004; Kershaw and Bulman, 1996; Harle et al., 2004; Cook and van der Kaars, 2006; van der Kaars et al., 2006).

Growing interest in the nature of past climates in terms of their influence on the history of flora and fauna (Crisp et al., 2004; Byrne et al., 2008), and for modelling the distribution of vegetation and species under past climatic conditions (Hugall et al., 2002; Martínez-Meyer et al., 2004; Hilbert et al., 2007; Banks et al., 2008; Nogués-Bravo et al., 2008), has resulted in Quaternary palaeoclimate data increasingly being utilised by researchers from outside the Quaternary community. The appropriate use of palaeoclimatic data requires that users are adequately informed in regard to the significance and limitations of specific palaeoclimatic reconstruction results.

This paper describes the details of a new approach to palaeoclimatic reconstruction in Australia using bioclimatic envelope data derived from modern beetle distribution records. It explicitly explores the uncertainties that arise when attempting to use bioclimatic data derived from the distribution of species in modern climate space and presents an approach that is relevant to other proxies and regions. An overview of Quaternary entomology with context and implications for the Australian record was presented by Porch and Elias (2000) and a review of Last Glacial sites by Porch (2007). Quaternary beetle assemblages have been recovered from a range of Australian sites spanning the Quaternary, the description and interpretation of which will appear in a series of papers that begins with Sniderman et al. (2009) and Porch et al. (2009).

\section{Aims}

If quantitative climate reconstructions are to be developed, refined and, importantly, to some extent reflect Quaternary reality, it is essential to have a detailed understanding of the potential and limitations of individual proxies and methods. This paper presents the context, rationale, and methods developed for the reconstruction of past climates in Australia using coexistence methods applied to beetle assemblages.

The aims of the paper are:

- To provide an assessment of considerations relating to the use of bioclimatic envelopes, based on modern taxa, derived from modern climate space, and how this potentially influences reconstruction of climatic parameters.

- To describe the methodological approach developed for the reconstruction of past climates using beetle assemblages in Australia.

- To assess the relative utility of employing a range of temperature and precipitation parameters in palaeoclimatic reconstructions.

- To test the method using modern jack-knifed assemblages and meteorological data.

- To clearly state the limitations of the method for reconstructing past climates in the context of modern and potential past climate space configurations.

- To assess the utility of the method developed in the context of previous research and alternative approaches.

\section{Background}

\subsection{The bioclimatic niche concept}

The nature of an organism's response to thermal and moisture regimes is determined by the unique physiology of the taxon (Kearney and Porter, 2004), which cannot practically, however, be experimentally determined for large assemblages of species. For large datasets the simplest way to determine thermal and moisture requirements is by derivation from the broad-scale relationships to environmental gradients. This 'bioclimatic envelope' method and its derivatives are widely used to predict the potential distribution of species from specimen collection records (Busby, 1986; Lindenmayer et al., 1991; Nix, 1991; Beaumont and Hughes, 2002; Hampe, 2004; Pearson et al., 2004; Beaumont et al., 2005; Pearson et al., 2007), to predict the response of species to climate change (Berry et al., 2002; Pearson and Dawson, 2003; Williams et al., 2003; Araújo et al., 2005; Thuiller et al., 2005), and to reconstruct past climates (Atkinson et al., 1987; Elias, 1997; Mosbrugger and Utescher, 1997; Moine et al., 2002; Marra et al., 2004).

In Australia, bioclimatic envelope methods have been used to reconstruct past climates using 'indicator' taxa (McKenzie and Busby, 1992; Lloyd and Kershaw, 1997; McKenzie and Kershaw, 1997) or assemblages (Kershaw and Nix, 1988, 1989; Kershaw, 1997), and to predict the past distribution of rainforest and rainforest biota in the wet tropics region of northeastern Australia (Nix, 1991; Williams, 1998; Hugall et al., 2002; Graham et al., 2006). The approach adopted here, and described below, builds on the seminal work of Kershaw and Nix $(1988,1989)$, which used the overlap of bioclimatic ranges of rainforest plants to reconstruct late Quaternary climates of the wet tropics region of northeastern Australia.

\subsection{Complexities of taxon-climate relationships}

In Quaternary science it is generally assumed that the current distribution pattern of an organism reflects the climate in which that taxon can exist. Therefore, Quaternary climates can be reconstructed in reference to the modern ecology- in this case bioclimatic envelope data- of taxa that occur in the fossil record (Coope, 1977; Bartlein, 1997; Birks, 2003). This is, potentially, only partly true. An organism may be able to exist in other climatic regimes, but is dispersal limited- that is, it cannot reach such suitable habitats because of physical barriers, or it may not be in equilibrium with modern climate because of its limited dispersal ability (Prentice, 1986; Guisan and Zimmermann, 2000; Pulliam, 2000; Gaston, 2003; Hampe, 2004; Araújo and Pearson, 2005). Alternatively, the full range of climates that exist today may not encompass the full range of climates in which a taxon could potentially exist (Jackson and Overpeck, 2000; Jackson and Williams, 2004) meaning we have a limited insight into the potential climatic significance of the taxon. Microclimatic effects may mean taxa may maintain themselves in habitats that would otherwise be outside their geographic and climatic range (Andersen, 1993). Finally, through human or other agency, an organism may have been regionally extirpated from a part of its potential climatic range, an issue generally neglected in the species climatic modelling community but well recognised in the Quaternary community (Dinnin and Sadler, 1999; Whitehouse, 2006; Porch, 2008).

\section{Methods}

\subsection{Modern Australian climate space}

A dataset that represents the modern climate space of the Australian region includes a total of 16,696 data points from across the continent (see Fig. 1). The majority of points $(16,484)$ are derived from a stratified sample (by latitude and longitude) of a continental scale $0.025^{\circ}$ digital elevation model- AUS40.DEM (CRES, 1999). The remaining 212 points represent supplementary data to ensure capture of topographic highs in montane regions. These points are derived from point elevation values from the Australian 1:250,000 topographic map series (AUSLIG, 2000) and represent mountain peaks from the principal mountain ranges of Australia. 


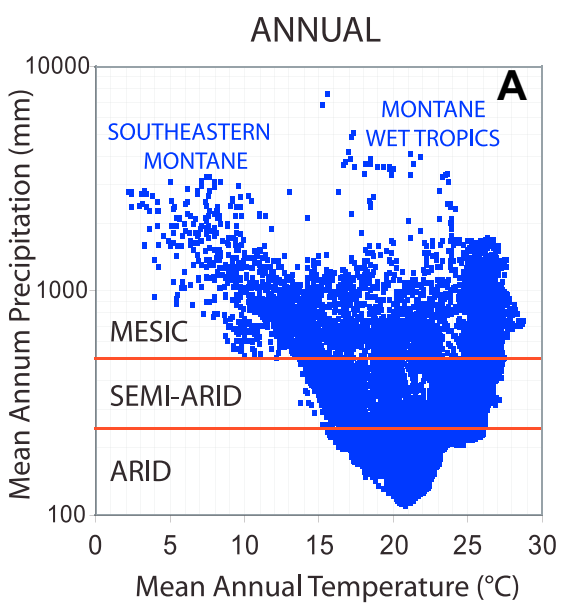

MAXIMUM/MINIMUM TEMP.

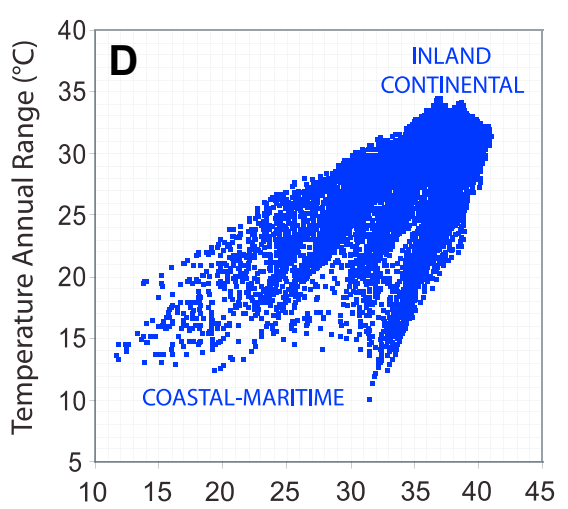

Max. Temp. of the Warmest Month $\left({ }^{\circ} \mathrm{C}\right)$
WARM SEASON

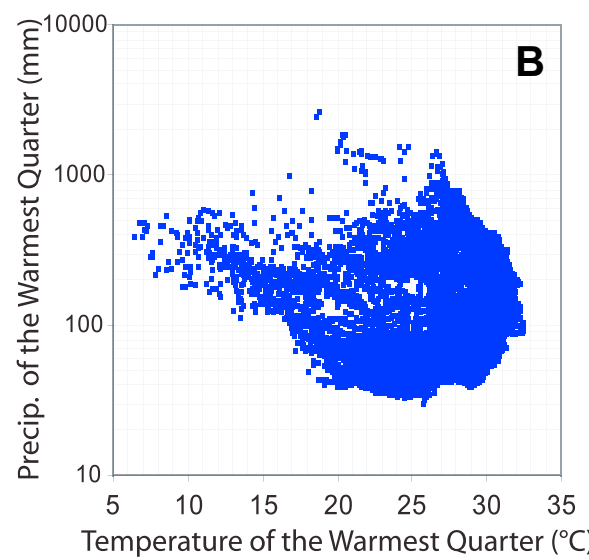

SEASONAL TEMPERATURE REGIME

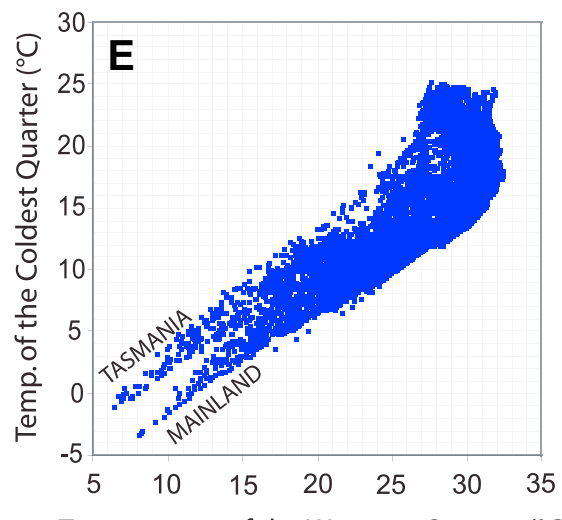

Temperature of the Warmest Quarter $\left({ }^{\circ} \mathrm{C}\right)$
COLD SEASON

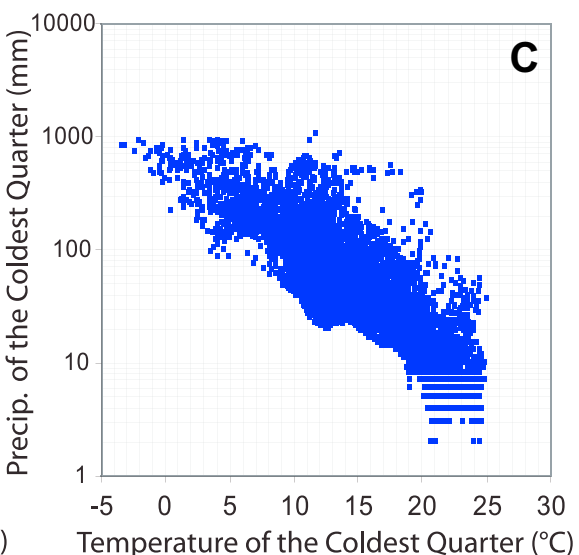

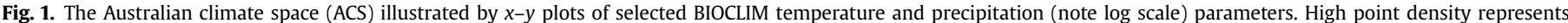

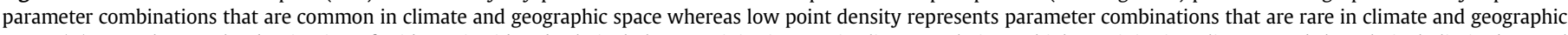

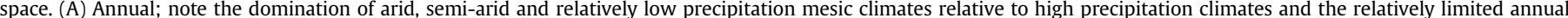

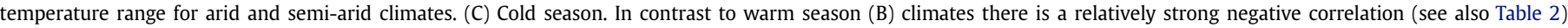

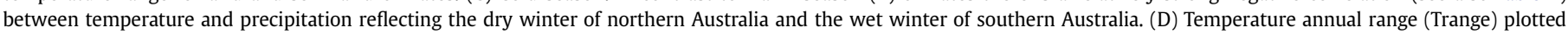

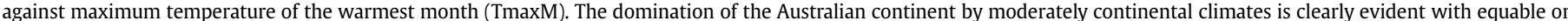

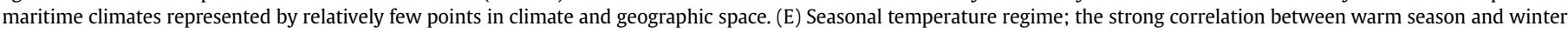

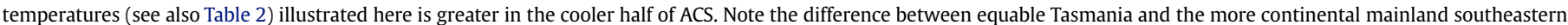

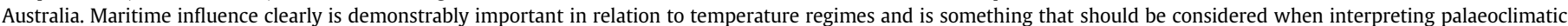

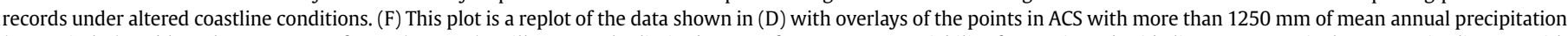

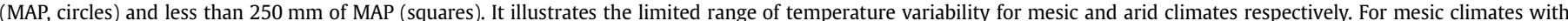

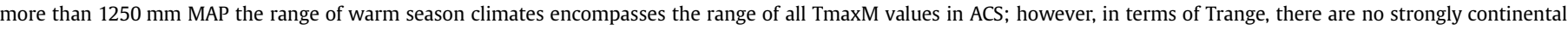

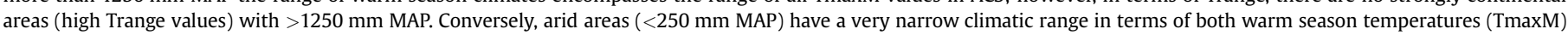
and annual range (Trange).

\subsection{Climate relationships for beetle taxa}

\subsubsection{Database of Australian beetle distribution}

Distribution and ecological records for most Australian species of aquatic, riparian and dung beetles and a selected range of further common taxa were assembled in a BioLink (Shattuck and Fitzsimmons, 2002) database. These data were derived from four principal sources: government and museum databases; literature records; museum records collated by the author; and field collections. Detailed distribution records are included for approximately 2400 species from 5500 separate collection localities (1-124 species per locality), adding up to a total of ca 80,000 individual records.

\subsubsection{Geocoding}

Approximately $95 \%$ of the 5500 localities included in the database have been assigned latitude and longitude values on the basis of their label data. The quality of geocodes is pivotal to developing accurate estimates of climatic parameters from a locality and questionable localities have been excluded from consideration in the bioclimatic model. Reasons for exclusion include: old records that refer to a region rather than a specific locality; records based on questionable identifications; multiple localities of the same name; and locality records substantially beyond a known range of a taxon. Altitudes for the remaining localities were derived from label data, and, where possible, from topographic maps. The use of digital elevation models to derive elevation was discounted due to the probability of substantial errors, especially in terrain with high relief (Rowe, 2006). In many cases, however, the accuracy of the elevation derived from topographic maps can be questioned due to the lack of specific detail provided in the description of the collection locality. If the collection locality could not be identified on the basis of the label data provided, such that the potential for elevation error was greater than $\pm 100 \mathrm{~m}$, the locality was excluded from further consideration. This reduced the number of three dimensionally geocoded localities to approximately 4100 . 


\subsubsection{Bioclimatic analysis of geocoded locality data}

BIOCLIM is a bioclimatic modelling program currently incorporated within the software package ANUCLIM 5.1 (Houlder et al., 2000). Using a thin-plate smoothing spine interpolation method, BIOCLIM interpolates climatic parameter values for geocoded (latitude, longitude, altitude) locations from climatic and physical data from a network of meteorological stations (Houlder et al., 2001). For Australia BIOCLIM uses a network of more than 1000 stations to derive temperature estimates and more than 15,000 stations to derive precipitation estimates; these are based on longterm mean values for temperature (1920-1995), precipitation (1920-1995), radiation (1920-1983) and pan evaporation (19201995) (Houlder et al., 2001). Previous versions of BIOCLIM allowed the estimation of 12 and 24 parameters for any point, compared with the current 35 . Table 1 lists all temperature and precipitation parameters produced by BIOCLIM.

Bioclimatic profiles were constructed for a total of 734 beetle species. Taxa were selected primarily because they were candidates for inclusion in the Quaternary record (aquatic, riparian and otherwise hygrophilic taxa), had been recovered from the fossil record, or belonged to groups that are commonly recovered from the fossil record elsewhere. For each of these taxa, a bioclimatic profile was derived from the three dimensionally geocoded data. Output includes a bioclimatic profile (.pro) that summarises, in terms of minima, maxima, percentile values and standard deviation, the climatic range of a taxon. An associated 'sites' file (.bio) summarises the parameter values for a taxon at each of the geocoded sites contributing to the bioclimatic profile.

\subsubsection{Contrasting responses to temperature and precipitation parameters}

Fig. 2 illustrates the distribution of 10 Australian beetle taxa in geographic space (the maps) and climate space ( $x-y$ plots)described by the intersection of warm season temperatures (temperature and precipitation of the warmest quarter: see below). The distribution maps clearly show that most taxa (like Chlaenius greyanus White in southwestern Australia and Hydaticus vittatus Fabricius in northern Australia, for example) are primarily restricted to marginal areas of the continent. This geographic

\section{Table 1}

Bioclimatic parameters estimated by BIOCLIM. Parameters 20-27 and 28-35 describe radiation and soil moisture indices and are not shown here or considered further.

\begin{tabular}{lll}
\hline No. & Parameter & Abbreviation \\
\hline 1 & Annual mean temperature & MAT \\
2 & Mean diurnal range (monthly maximum) & Tmdr \\
3 & Isothermality (parameter 2/parameter 7) $_{\text {pran }}$ & Tiso \\
4 & Temperature seasonality (coefficient of variation) $^{\text {a }}$ & Tseas \\
5 & Maximum temperature of warmest period & TmaxM \\
6 & Minimum temperature of coldest period & TminM \\
7 & Temperature annual range (5 - 6) & Trange \\
8 & Mean temperature of wettest quarter & TwetQ \\
9 & Mean temperature of driest quarter & TdryQ \\
10 & Mean temperature of warmest quarter & TwarmQ \\
11 & Mean temperature of coldest quarter & TcoldQ \\
12 & Mean annual precipitation & MAP \\
13 & Precipitation of wettest period & PwetM \\
14 & Precipitation of driest period & PdryM \\
15 & Precipitation seasonality (C of V) & Pseas \\
16 & Precipitation of wettest quarter & PwetQ \\
17 & Precipitation of driest quarter & PdryQ \\
18 & Precipitation of warmest quarter & PwarmQ \\
19 & Precipitation of coldest quarter & PcoldQ \\
\hline
\end{tabular}

a BIOCLIM allows use of month or week time step for period. For the purpose of this project period refers to a month (consecutive 5 weeks rather than calendar month). In the remainder of this paper 'period' will be replaced with 'month'.

b In BIOCLIM Quarter refers to 13 consecutive weeks.

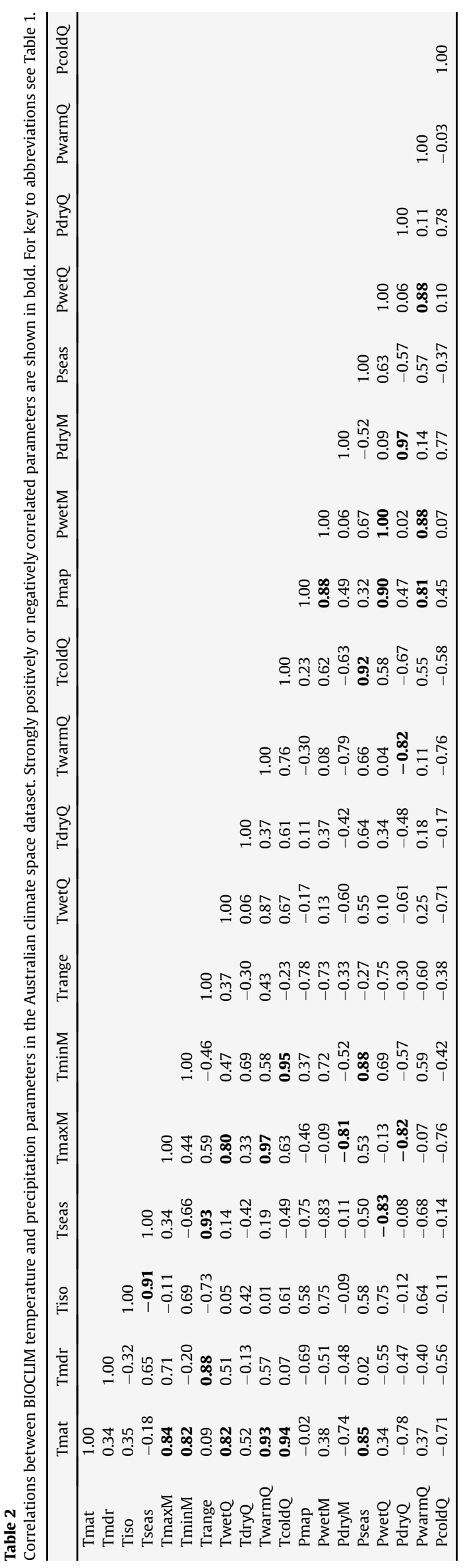



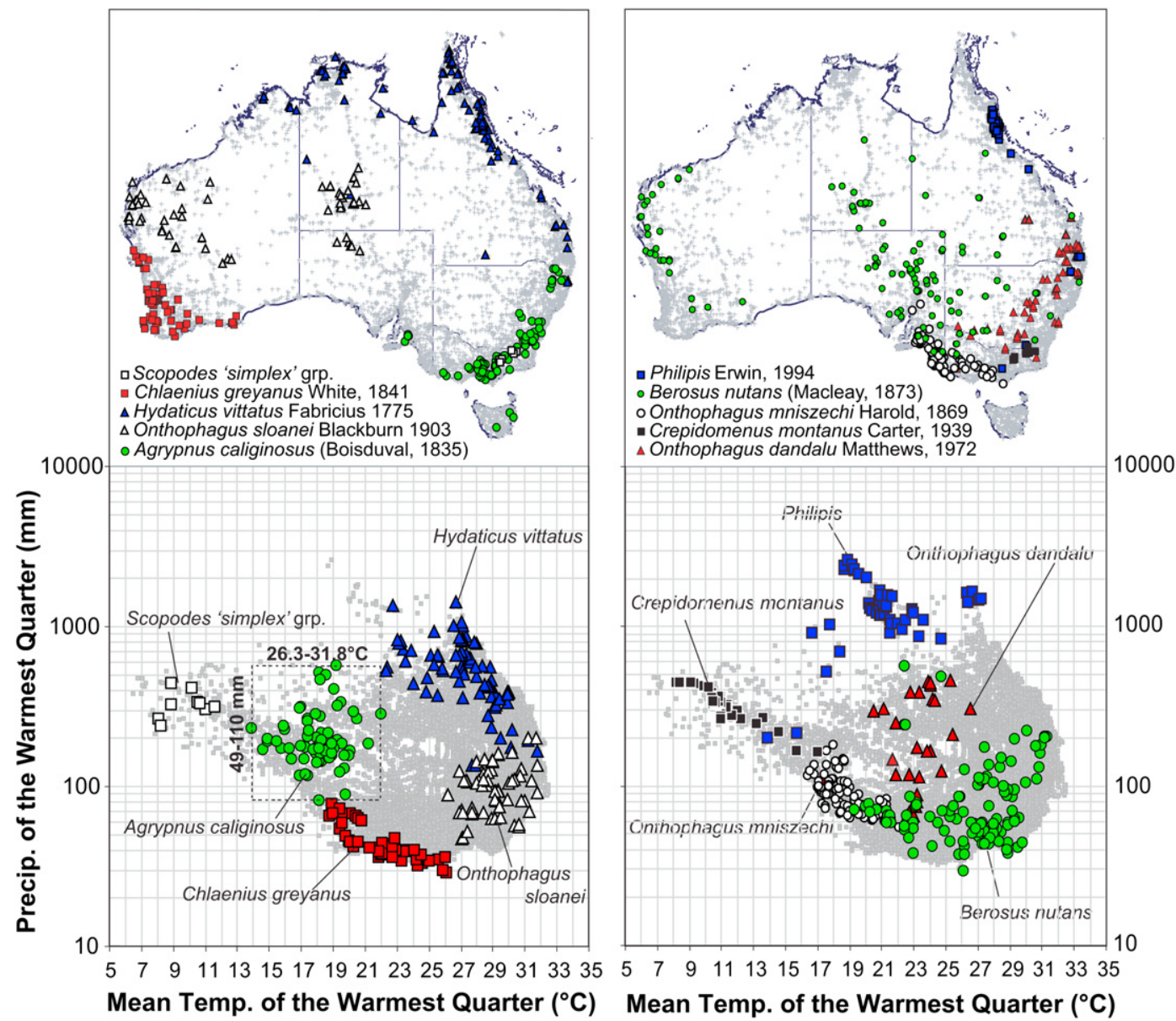

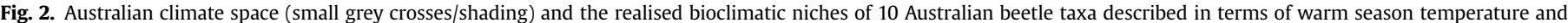

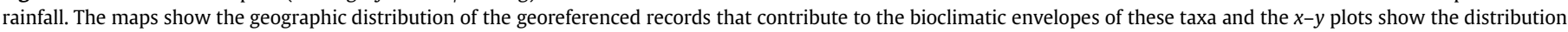

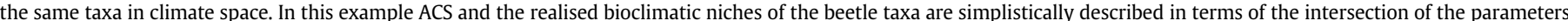

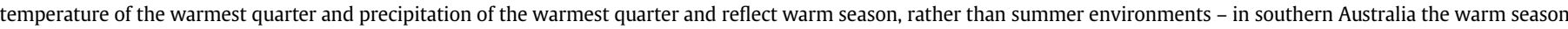

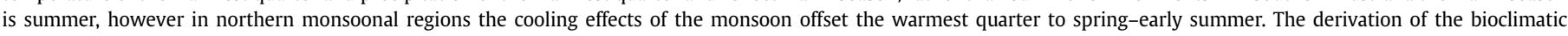

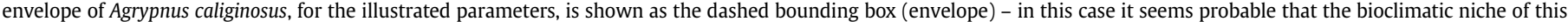

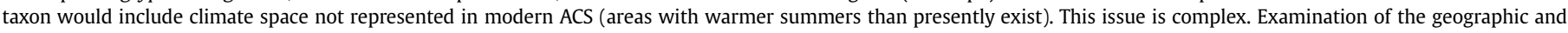

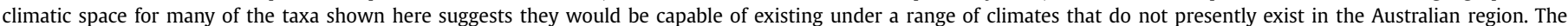

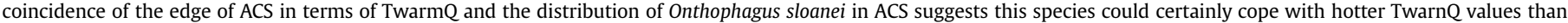

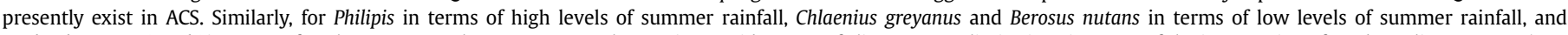

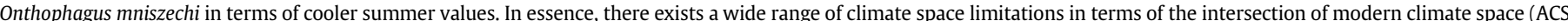

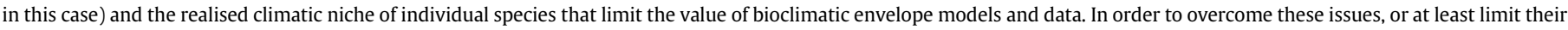
impact, it would be necessary to examine their consequences on each taxon individually, something well beyond the scope of this paper.

restriction reflects the extant arrangement of temperature and precipitation regimes relative to the bioclimatic niche of the species.

Histograms of temperature relationships approach normal with the majority of records derived from a relatively narrow climatic range, when compared with the total climatic range of the taxon (Fig. 3). In contrast, precipitation relationships are positively skewed for taxa from mesic regions, but less so, or not at all, for taxa from xeric regions; this skew in precipitation parameters reflects the variability of influence of moisture regimes in determining or limiting the distribution of beetle, and other, species. In mesic regions most species are almost certainly able to cope with higher moisture levels than exist in the modern climate. In this case the positive skew represents the relative rarity of high precipitation environments in Australian climate space and therefore the low frequency of records from such regions in bioclimatic profiles, because of the unlikelihood of collection from these spatially restricted habitats. In contrast, for taxa adapted to xeric environments, upper moisture limits are physiologically limiting and there are few climate space issues.

\subsection{Error estimation}

Large numbers of collection localities for a stenotopic taxon are adequate to describe its bioclimatic profile; however, the distribution data for less well-collected taxa, especially if they are eurytopic, will underestimate their realised bioclimatic niche. I agree with the argument of Marra et al. (2004), in reference to developing palaeoclimatic reconstruction methods using New Zealand beetle assemblages, that comparatively poor modern datasets necessitate a method of estimating the error associated with estimating climatic range based on a limited modern dataset. This is similarly true for Australia.

It is impossible to assess the value of error estimates without resort to at least one of two methods. These are: 

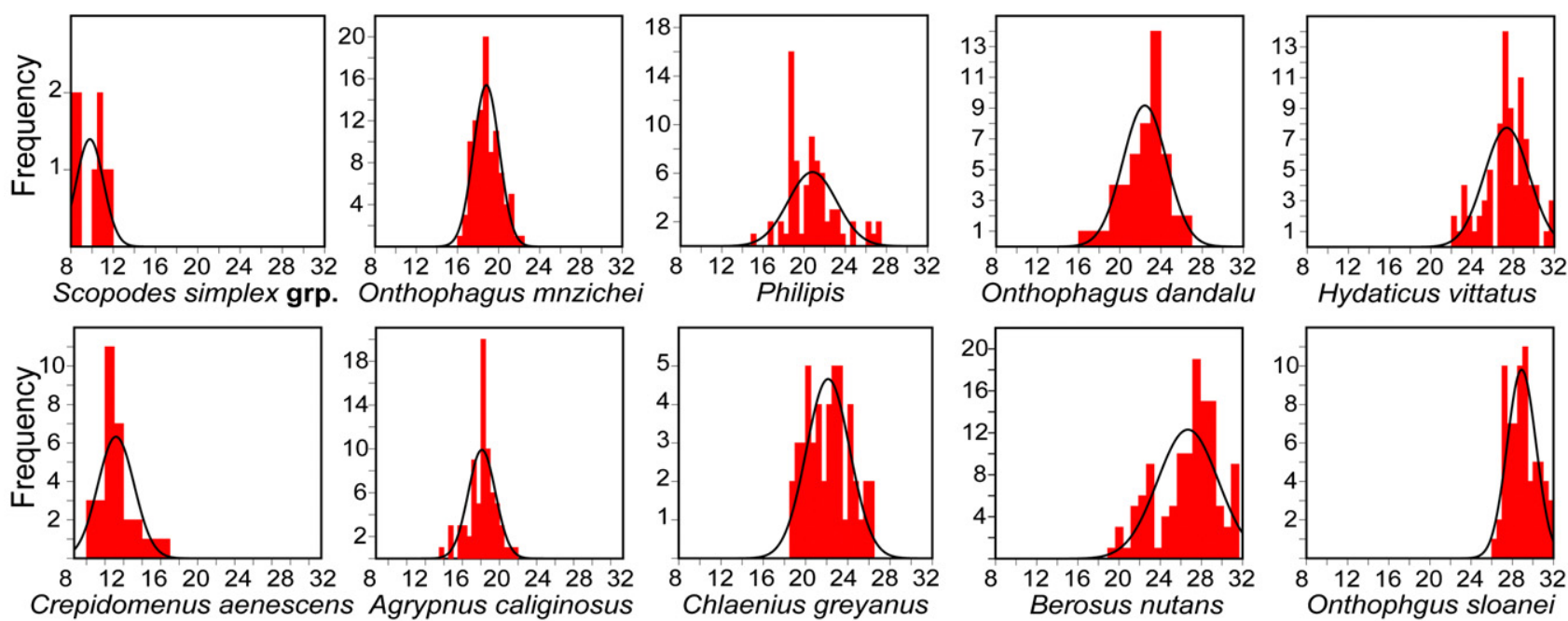

Temperature of the Warmest Quarter $\left({ }^{\circ} \mathrm{C}\right)$
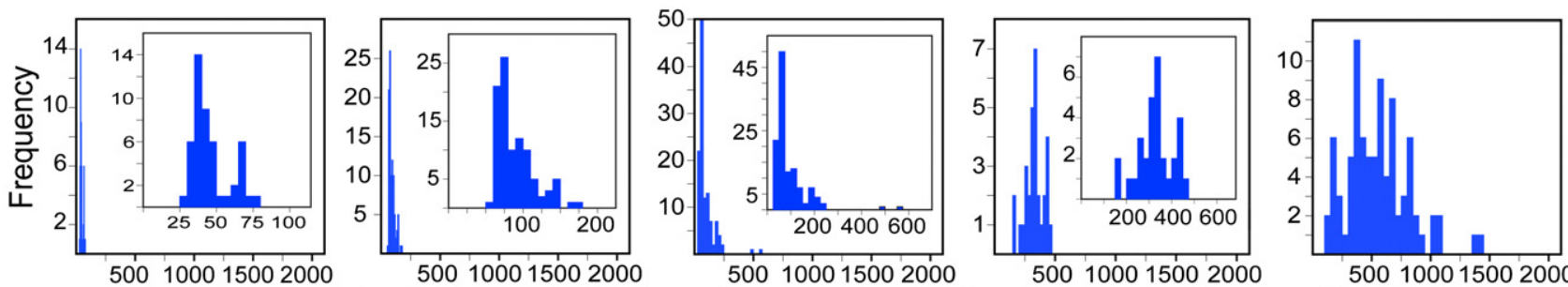

Chlaenius greyanus

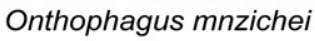

Berosus nutans
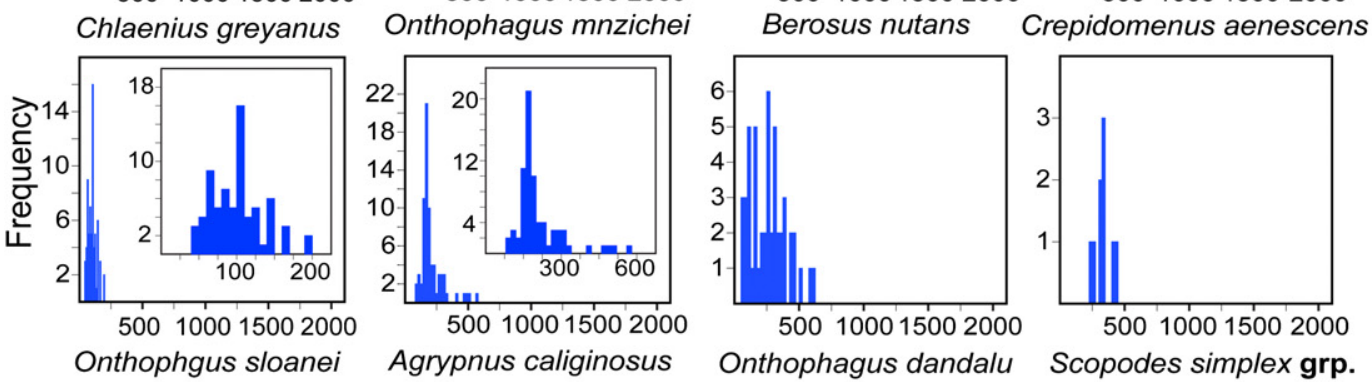

500100015002000 Hydaticus vittatus

Agrypnus caliginosus

Onthophagus dandalu

500100015002000

Precipitation of the Warmest Quarter $(\mathrm{mm})$

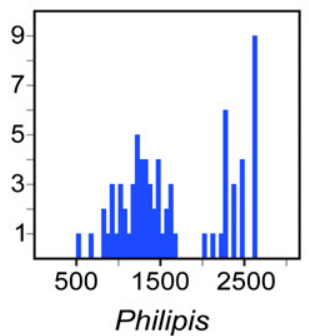

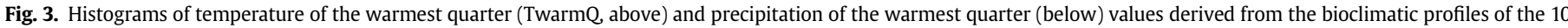

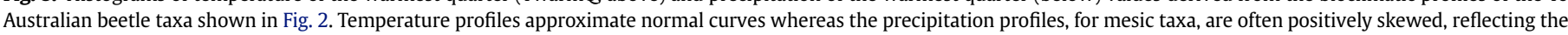

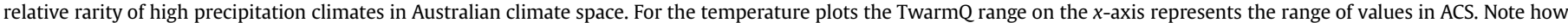

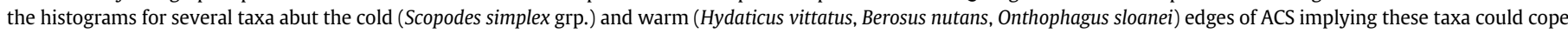

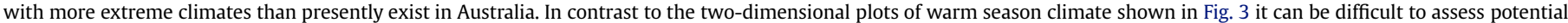

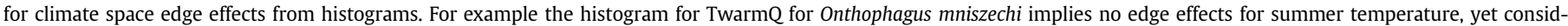

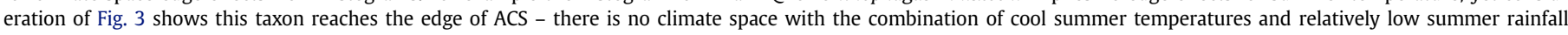
available in ACS in which 0 . mniszechi could potentially occur.

(1) comparison of data-poor bioclimatic envelopes with data enhanced profiles arising from increased access to new distributional data (new collections, access to previously inaccessible or unacknowledged data);

(2) testing the accuracy and precision of the method using jackknifed modern assemblage data.

I use the former approach to assess the most reliable method for estimating error and then the latter approach to test the reliability of the method adopted.

A range of methods of estimating the bioclimatic range from incomplete distributional data were examined; none were entirely satisfactory, primarily because it is impossible to predict whether the actual bioclimatic limits of a taxon was represented in the available distributional data and, secondly, because modern collection strategies generally violate the assumption of random sampling. The most reliable method for ensuring that the actual bioclimatic limit of the taxon was included in the estimated range of a particular temperature parameter was by comparing the effect of increasing data quality on the range of the parameter. For some species more than one bioclimatic profile was produced during the course of the project because new distributional data became available: this sometimes doubled (or rarely trebled) the number of records for a taxon. Comparison of the initial bioclimatic profiles with the increasingly well-resolved profiles meant that it was possible to examine the effect of increased data quality on the range of bioclimatic parameters.

For temperature parameters, iterative examination of the relationship between old and new parameter ranges for 50 species indicated that the old profile maximum plus four times the range per record value, and the old profile minimum minus four times the range per record value, included both the new profile maximum 
and minimum in approximately $90 \%$ of cases, generally with some overlap, and was the most effective method for determining errors whilst retaining the precision of the estimated range. In less than $10 \%$ of cases (four species), there was underestimation of the new profile parameter maxima or minima by less than $1^{\circ} \mathrm{C}$; in less than $5 \%$ of cases (two species) underestimation was by more than $1^{\circ} \mathrm{C}$. These instances all involved the doubling or trebling of the number of records from a relatively large number of initial records, suggesting that the errors arise when extreme values are encountered, like those at the margins of the actual bioclimatic range of a species. This possibility is less likely for taxa with an initially small number of records because of their initially large range per record value, and consequently larger estimated range meant that these extremes, when encountered, were included within the estimated range. In these cases it is likely the estimated parameter range overestimates the actual bioclimatic range for the species. For precipitation a similar, but slightly different approach was taken to limit the influence of infrequent high values on minimum value estimates. In this case, rather than using the entire range for the minimum estimate, the range/record value excludes the upper quartile (raw data minimum minus five times $0-75 \%$ range per record value). For the maximum estimate the entire range of the raw data is used (raw data maximum plus five times parameter range per record value).

The estimated ranges of the bioclimatic profiles are referred to as estimated parameter ranges (EPR) to contrast them with the raw data represented in the bioclimatic profiles. In essence, EPR values mainly serve to decrease the precision of assemblage-based estimates compared with raw data value estimates, but are more likely to reflect real uncertainties that are based on the lack of perfect knowledge of the distribution of taxa in modern climate space.

\subsection{Climatic parameter reconstruction}

Assemblage-based approaches to palaeoclimatic reconstruction frequently rely on establishing the overlap of climatic parameter values for taxa in a given assemblage. This approach, in various forms, is commonly utilised in Neogene palaeoclimatology. Here I refer to the approach utilised as the coexistence approach following Mosbrugger and Utescher (1997) in order to distinguish it from alternative beetle-based approaches like mutual climatic range (Atkinson et al., 1986; Sinka and Atkinson, 1999) and maximum likelihood envelope (Marra et al., 2004). It should be noted that in this context the term 'coexistence' refers to potential coexistence (in terms of climatic parameters) rather than range overlap in geographic space. For approaches that utilise parameter overlap the structure of modern data is fundamental to understanding the value of individual bioclimatic profiles and therefore the utility of the reconstruction. Box-plots represent the best combination of data transparency and usability and are a preferred method of presenting information that describes the nature and structure of data. Minimum-maximum (range) plots conceal information on data quality and, when displayed without further information on the number of records contributing to the range, may represent as few as two data points.

For each taxon, data for climatic parameters is derived from the BIOCLIM sites file (.bio) as noted above. For each assemblage, and for each reconstructed parameter, a series of box-plots summarise the climatic responses of the individual taxa contributing to the assemblage. The data summarised by each box-plot are the raw data derived from the bioclimatic profile of the taxa. The estimated parameter range (EPR) value, calculated for each parameter and for each taxon, is represented as a bar that extends the raw data range summarised in the box-plot. The predicted parameter range for either a modern or a fossil assemblage is defined by the highest minimum value and the lowest maximum value for the range of taxa contributing bioclimatic data to the assemblage (see Fig. 4). In order to test the value of the method the modern tests were jackknifed: parameter values for the species at a test site were excluded from the beetle-based prediction of the climates climate. Finally, to assess the relative utility of different ecological groups a series of five assemblages were independently assessed. These are: 'All Taxa' representing all species in an assemblage, 'Aquatic' including only obligate aquatic species, 'Dung/Saprophilic' including dung
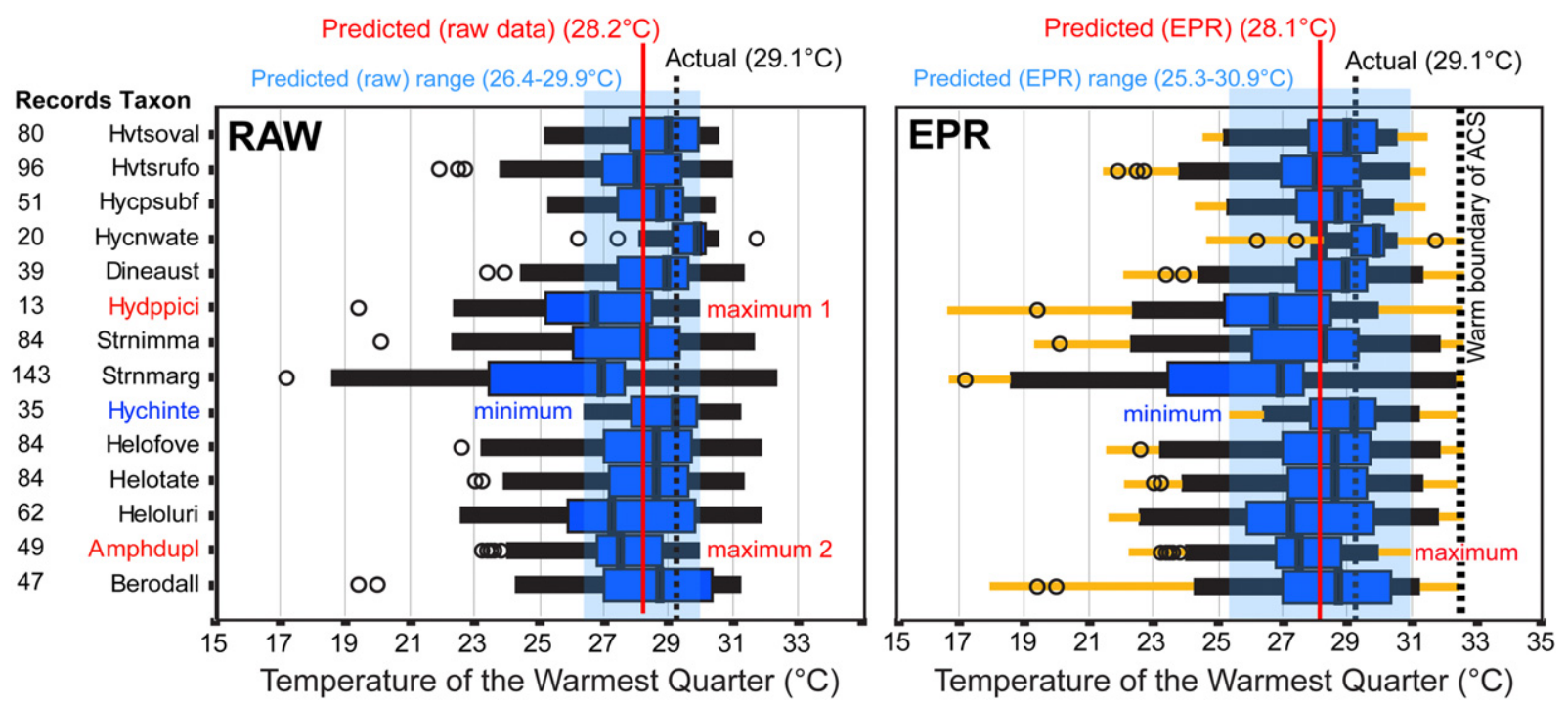

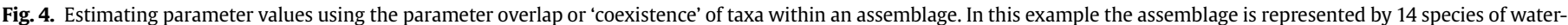

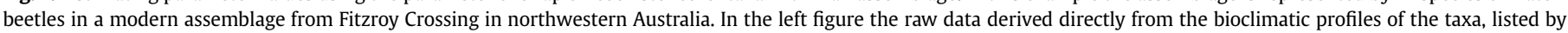

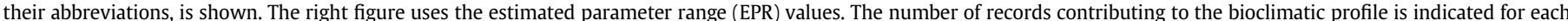

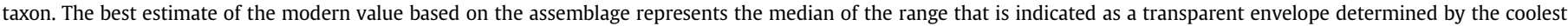

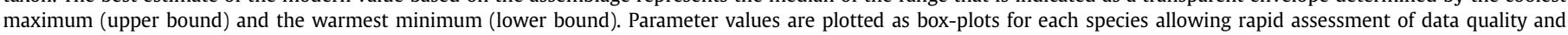

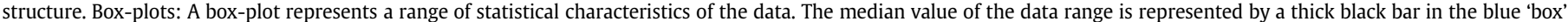

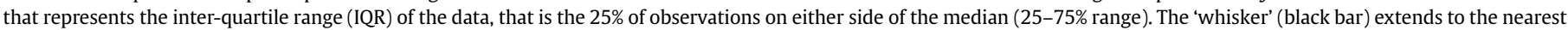

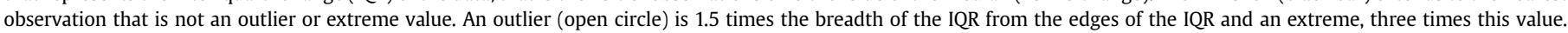


beetles and leaf litter obligates, 'Forest' representing wet forest species, and 'Riparian' including only marginal aquatic species of ground beetles.

\section{Results}

\subsection{Australian climate space}

Strong correlations exist at the continental scale between many parameters in the ACS dataset (Table 2). For example, seasonal temperature extremes (e.g. maximum temperature of the warmest month - TmaxM) are highly correlated with seasonal temperature averages (e.g. temperature of the warmest quarter- - TwarmQ) and mean annual temperature is, unsurprisingly, highly correlated with seasonal averages (TwarmQ, TcoldQ) and to a lesser degree with seasonal extreme values (TmaxM, TminM). Annual temperature range (Trange) is least correlated with the other parameters although moderately correlated with TmaxM, reflecting increasing temperature seasonality and increasing summer maximum temperatures in inland Australia. It is important to consider, however, that correlations across a continent statistically subsume local and regional variability in the relationships between parameters that may be of biotic significance.

For precipitation parameters strong continental scale correlations exist for a range of seasonal and annual parameters (Table 2), however, the issue of regional variability being subsumed into broad-scale continental correlations is magnified, relative to temperature parameters. At the continental scale precipitation of the warmest quarter (PwarmQ) is highly correlated with precipitation of the wettest quarter (PwetQ). This results from the spatial domination of tropical monsoonal climates in the north, and summer rainfall climates in eastern and much of central Australia. In southwestern Australia the relationship between PwetQ and PwarmQ is inverse to the continentally dominant trend because southwestern Australia has a winter dominated rainfall regime. For this reason the ecological significance of strong correlations between certain parameters at the continental scale need to be considered in light of the contribution that spatially dominant climate systems make to the correlation.

\subsection{Reconstructed temperature parameters}

Fig. 5 illustrates the observed versus beetle-predicted results for six temperature parameters. For each parameter and each assemblage category Table 3 presents correlation coefficients based on linear and polynomial (3rd order), regressions (strength of the relationship), standard deviations of the differences (SDD) between observed and predicted values (precision of predictions), and the percentage of observed values that fall within the predicted range (test of jack-knifing). The difference between linear and polynomial regression-based correlation coefficients is a measure of the influence of edge effects on the parameter; similar results indicate edge effects are relatively insignificant. The SDD values are a measure of the precision of predictions; smaller values mean that predictions are more precise but are best compared across categories within a parameter because the range of the parameter in climate space is not taken into account. The number of assemblages where the observed value falls within the predicted range includes only those where the difference between the observed value and the predicted range is greater than the error associated with BIOCLIM temperature estimates $\left(0.5^{\circ} \mathrm{C}\right)$; this reflects the possibility that, in such cases, the failure to overlap represents the estimation error of BIOCLIM.

Observed values fall within the jack-knifed predicted range for $96.8 \%$ of all assemblages and the average value for each parameter exceeds 95\%. Results for the All Taxa category range between $94.4 \%$ and $98.1 \%$ (Table 3 ) and average 95\%. Examination of assemblages that fail to overlap the observed value indicate two principal contributing factors. The first is assemblages at the extremes of climate space; in this case excluding extreme values from the bioclimatic profile of taxa in the assemblage results in underestimation of highs or overestimation of lows because there are no such extreme localities represented for each of the taxa in the assemblage. The second is the occurrence, in an assemblage, of a taxon in a location at the edge of its geographic range (often further south than the major part of its geographic range); in this case the occurrence of an extreme value in the bioclimatic profile of a well-collected taxon, when excluded during jack-knifing, pulls the assemblage toward its core range. It is likely that, in some cases, especially of the latter situation, that misidentification of specimens may contribute to lack of overlap of the predicted range and observed value. Of a total of 1248 individual combinations of assemblage, parameter, and taxon categories there are only two instances of taxa in an assemblage failing to overlap after jackknifing.

Results based upon the complete assemblage (All Taxa) suggest that estimates of MAT, TwarmQ and TcoldQ to within about $1-2{ }^{\circ} \mathrm{C}$, are routinely possible, reflecting the strong correlations between the observed and predicted values; SDD: MAT, $1.3^{\circ} \mathrm{C}$; TwarmQ $1.2^{\circ} \mathrm{C}$; TcoldQ $1.6^{\circ} \mathrm{C}$ (Table 3 ). Dung/Scarab taxa give very similar results, reflecting the stenotopic nature of many dung beetle taxa. Significantly, aquatic taxa alone give less accurate results (SDD: 1.6$2.0^{\circ} \mathrm{C}$ ); however, they allow the prediction of warm season climates independently of precipitation effects (see below). The less precise results for TmaxM and TminM (SDD values: Table 3) reflect the larger range of these parameters in climate space, relative to MAT, TwarmQ and TcoldQ, rather than the lack of predictive accuracy. The strong relationship between number of taxa and the precision of the predicted value compared to the observed value is illustrated in Fig. 6. As number of taxa with bioclimatic profiles included in an assemblage increases, the difference between observed and predicted values diminish rapidly - for 10 of the 11 assemblages with more than 20 included taxa, this difference is less than $1{ }^{\circ} \mathrm{C}$.

\subsection{Reconstructed precipitation parameters}

The results for precipitation parameters (Fig. 7 and Table 4) are not as satisfying as those for temperature parameters, although they bear out some of the assumptions discussed previously. As expected, aquatic taxa perform poorly for most parameters, supporting the assumption that they are relatively independent of precipitation influences. The Dung/Saprophilic category performs better than the other ecological categories, contributing to the overall better results for the All Taxa category. On the basis of the results for the modern test sites, it is unlikely that predictions of precipitation parameters using the best estimate (median of predicted range) are as accurate as the temperature predictions; they nonetheless are strongly indicative of precipitation regimes.

Examination of the taxonomic composition of assemblages from sites that have large differences between observed and predicted values of mean annual precipitation (MAP) for the All Taxa category shows them to be largely dominated by aquatic or hygrophilic taxa. For All Taxa and for the Dung/Saprophilic category, the minimum of the predicted range provides a good estimate of the observed value for sites with less than $700 \mathrm{~mm}$, rather than the 'best estimate' or middle of the predicted range. For sites with more than $700 \mathrm{~mm}$, this pattern breaks down, with the best estimate value usually providing a better prediction, although above $1200 \mathrm{~mm}$ these values underestimate the observed values at most sites. This 


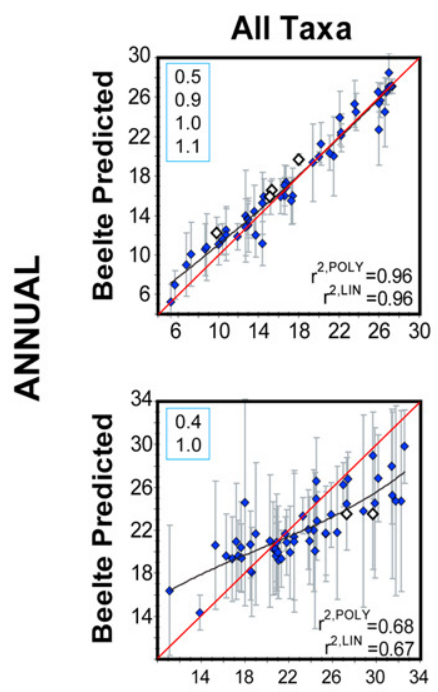

Aquatic

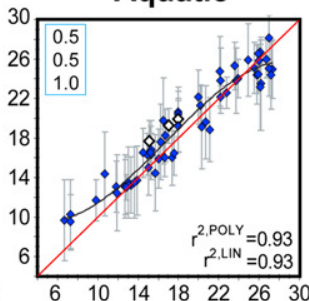

Dung/Saprophilic

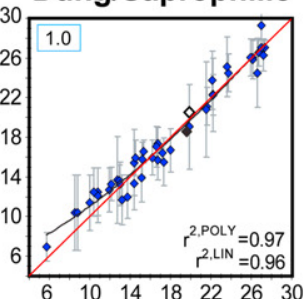

Annual Mean Temperature $\left({ }^{\circ} \mathrm{C}\right)$ - Observed
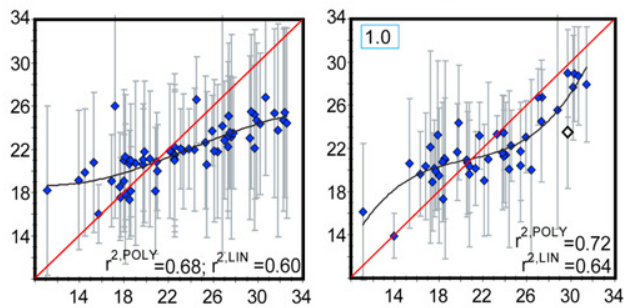

Annual Temperature Range $\left({ }^{\circ} \mathrm{C}\right)$ - Observed
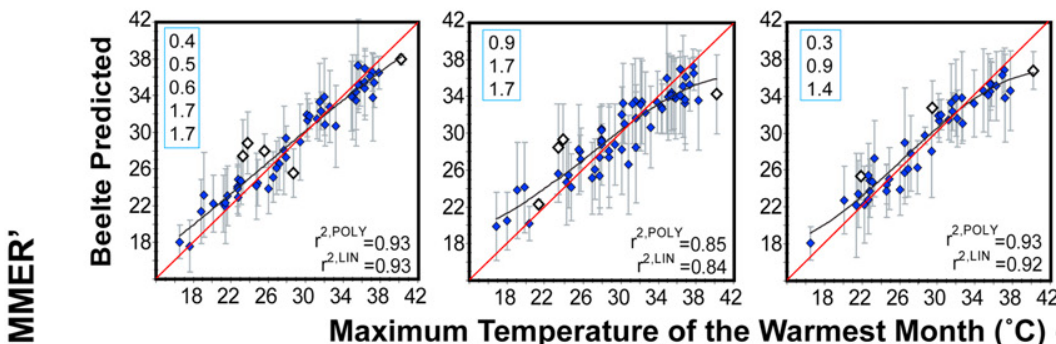

$\begin{array}{llllllll}18 & 22 & 26 & 30 & 34 & 38 & 42\end{array}$
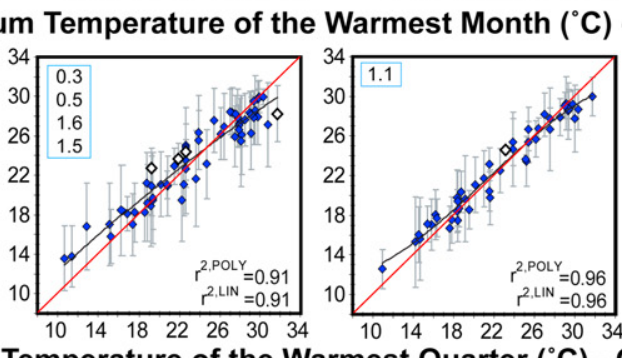

$\begin{array}{lllllll}10 & 14 & 18 & 22 & 26 & 30\end{array}$

Mean Temperature of the Warmest Quarter $\left({ }^{\circ} \mathrm{C}\right)$ - Observed
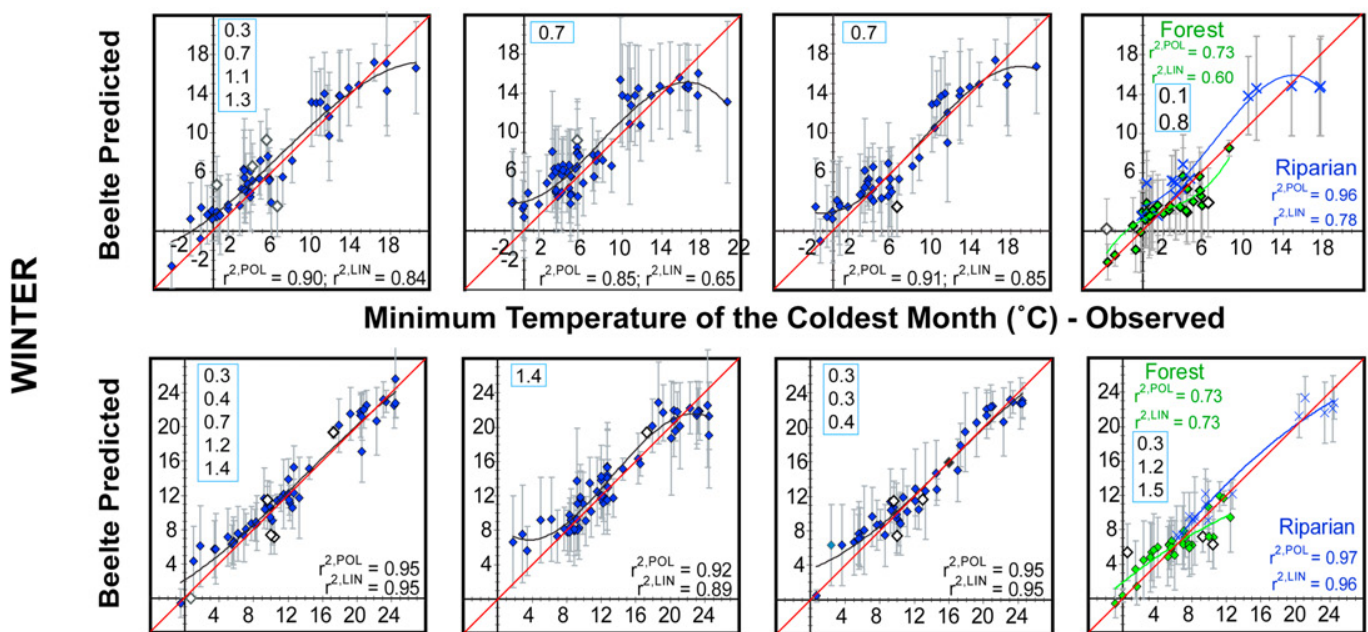

Minimum Temperature of the Coldest Month $\left({ }^{\circ} \mathrm{C}\right)$ - Observed
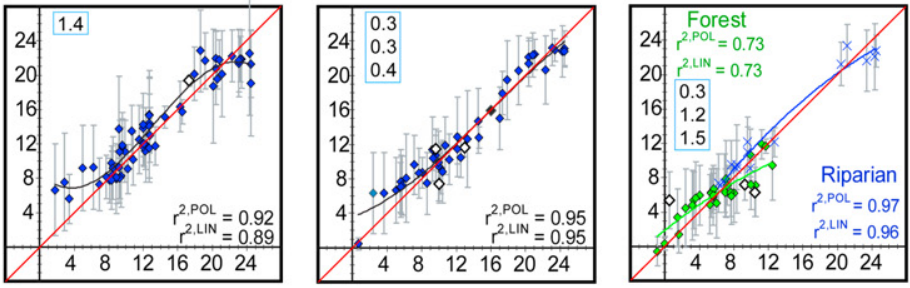

Mean Temperature of the Coldest Quarter $\left({ }^{\circ} \mathrm{C}\right)$ - Observed

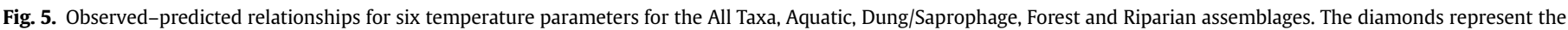

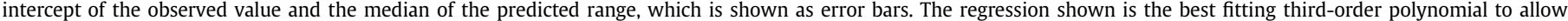

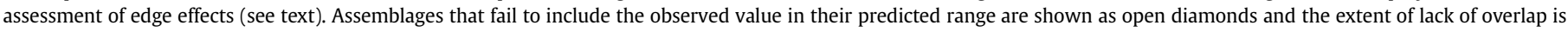
presented in boxes. 
Table 3

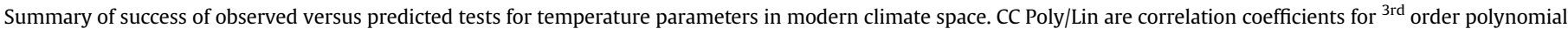

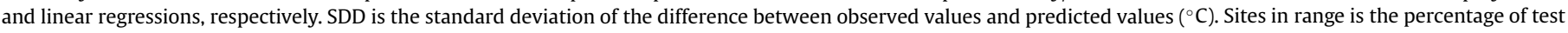
sites for which the observed value falls within the jack-knifed predicted range.

\begin{tabular}{|c|c|c|c|c|c|c|}
\hline \multicolumn{2}{|c|}{ Temperature } & \multicolumn{5}{|l|}{ Test groups } \\
\hline Paramete & & \multirow{2}{*}{$\frac{\text { All taxa (54) }}{0.96 / 0.96}$} & \multirow{2}{*}{$\begin{array}{l}\text { Aquatic (63) } \\
0.93 / 0.93\end{array}$} & \multirow{2}{*}{$\begin{array}{l}\text { Dung (46) } \\
0.97 / 0.96\end{array}$} & \multirow{2}{*}{$\frac{\text { Forest (32) }}{0.83 / 0.80}$} & \multirow{2}{*}{$\begin{array}{l}\text { Riparian (14) } \\
0.96 / 0.95\end{array}$} \\
\hline Tmat & CC Poly/Lin & & & & & \\
\hline & $\operatorname{SDD}\left({ }^{\circ} \mathrm{C}\right)$ & 1.3 & 1.6 & 1.1 & 1.6 & 1.6 \\
\hline & Sites in range (\%) & 94.4 & 98.4 & 97.8 & 96.9 & 92.1 \\
\hline \multirow[t]{3}{*}{ Trange } & CC Poly/Lin & $0.65 / 0.64$ & $0.61 / 0.60$ & $0.72 / 0.64$ & $0.37 / 0.34$ & $0.84 / 0.60$ \\
\hline & $\operatorname{SDD}\left({ }^{\circ} \mathrm{C}\right)$ & 3.1 & 3.7 & 3.0 & 2.4 & 3.0 \\
\hline & Sites in range (\%) & 98.1 & 100 & 97.8 & 100 & 100 \\
\hline \multirow[t]{3}{*}{ TmaxM } & CC Poly/Lin & $0.93 / 0.93$ & $0.85 / 0.84$ & $0.93 / 0.92$ & $0.74 / 0.71$ & $0.96 / 0.92$ \\
\hline & $\operatorname{SDD}\left({ }^{\circ} \mathrm{C}\right)$ & 1.8 & 2.3 & 1.8 & 1.7 & 1.6 \\
\hline & Sites in range (\%) & 94.4 & 95.2 & 95.7 & 100 & 100 \\
\hline \multirow[t]{3}{*}{ TwarmQ } & CC Poly/Lin & $0.96 / 0.96$ & $0.91 / 0.91$ & $0.96 / 0.96$ & $0.81 / 0.81$ & $0.94 / 0.94$ \\
\hline & $\operatorname{SDD}\left({ }^{\circ} \mathrm{C}\right)$ & 1.2 & 1.7 & 1.2 & 1.4 & 1.5 \\
\hline & Sites in range (\%) & 94.4 & 96.8 & 97.8 & 100 & 92.3 \\
\hline \multirow[t]{3}{*}{ TminM } & CC Poly/Lin & $0.90 / 0.84$ & $0.85 / 0.65$ & $0.91 / 0.85$ & $0.73 / 0 / 60$ & $\mathbf{0 . 9 6} / 0.78$ \\
\hline & $\operatorname{SDD}\left({ }^{\circ} \mathrm{C}\right)$ & 1.9 & 2.3 & 1.9 & 1.7 & 2.2 \\
\hline & Sites in range (\%) & 94.4 & 98.4 & 97.8 & 96.9 & 92.3 \\
\hline \multirow[t]{3}{*}{ TcoldQ } & CC Poly/Lin & $0.95 / 0.95$ & $\mathbf{0 . 9 2} / 0.89$ & $0.95 / 0.95$ & $0.73 / 0.73$ & $0.97 / 0.96$ \\
\hline & $\operatorname{SDD}\left({ }^{\circ} \mathrm{C}\right)$ & 1.6 & 2.0 & 1.5 & 1.9 & 1.5 \\
\hline & Sites in range (\%) & 94.4 & 98.4 & 100 & 93.7 & 100 \\
\hline
\end{tabular}

pattern holds for PwetM, PwetQ and PwarmQ. For PdryM, PdryQ PcoldQ and precipitation seasonality (Pseas) the best estimate values provide a good prediction of the observed values, although there are wide ranges and, consequently, substantial errors for some assemblages, many related to the inclusion of assemblages dominated by aquatic and hygrophilic taxa.

In light of these factors, an observation that must be considered when assessing the results presented and discussed above is that the predicted range is meaningful regardless of whether the best estimate is close to the observed value. Consequently, if the predicted range for a parameter is wide, then it is quite possible the best estimate is really a poor indicator of the true value for the modern or fossil assemblage. Conversely, when the predicted range is narrow the best estimate must by necessity be close to the true value.

\section{Discussion}

\subsection{Parameters for palaeoclimatic reconstruction}

The parameters mean diurnal range (Tmdr), temperature isothermality (Tiso), and temperature seasonality (Tseas) are not

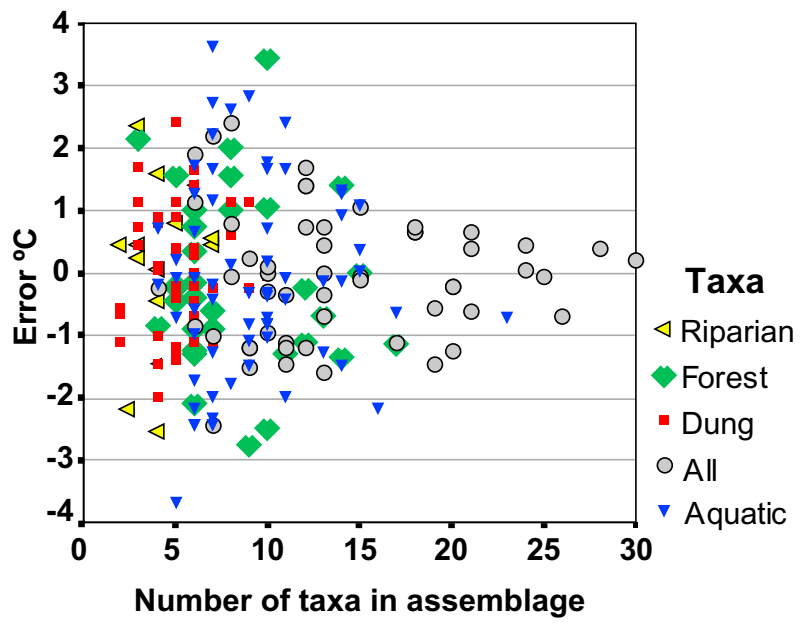

Fig. 6. Relationship between number of taxa in an assemblage and the prediction error for the parameter Temperature of the Warmest Quarter (difference between observed and predicted value). The accuracy of the prediction increases markedly with increasing numbers of taxa represented in the assemblage. considered further for several reasons: in the modern tests they performed poorly (Tmdr, Tseas); the potential influence on alternative climate spaces is difficult to assess (Tmdr, Tiso); they are generally moderately well correlated with mean annual temperature (Tmdr, Tseas), which has been included, or there are good reasons why they may not be significantly influential on the distribution of beetles (Tiso, Tmdr). Temperature of the wettest and driest quarters have been excluded because of the lack of discrimination of temperature seasonality and are subsequently difficult to interpret in Quaternary contexts- the timing of the wettest or driest quarter would remain unclear making the thermal significance of the parameter difficult to interpret. Several parameters that are potentially subject to significant limitations when reconstructing Quaternary climates have been included in the set of parameters for reconstruction. Issues relating to these parameters are discussed in the following section.

The best performing temperature parameters were MAT, TmaxM, TwarmQ TminM and TcoldQ all of which were reconstructed successfully and with precision in modern climate space. The strong correlation in ACS, however, between the warm season parameters, the cold season parameters, and to some extent MAT, suggests that it may be realistic only to attempt reconstruction of a single warm season and/or single cold season parameter. Given the biological significance of warm season temperatures and probable lack of significance of cold season temperatures in the Australian context, TwarmQ which measures overall summer warmth, is considered the most reliable parameter for reconstruction.

Only three precipitation parameters (MAP, PwarmQ, PcoldQ) need to be reconstructed to describe the annual and seasonal moisture regimes across the continent. The parameters PdryM, PwetM, PdryQ and PcoldQ, although reliably reconstructed, are, as discussed above, subject to precipitation seasonality influences, making meaningful comparison across the continent impossible.

\subsection{Considerations pertinent to Quaternary application}

\subsubsection{Comparison with alternative approaches to quantification}

Several methods have been used for quantification of past climates using fossil beetle assemblages. The mutual climatic range (MCR) method is frequently used to reconstruct seasonal temperature regimes, using beetle assemblages and other taxa, in Europe 
Table 4

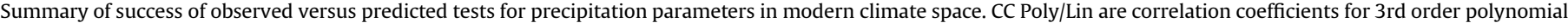

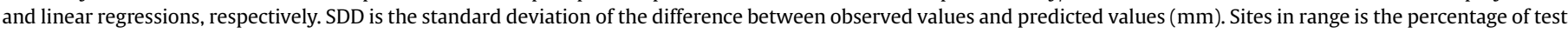
sites for which the observed value falls within the jack-knifed predicted range.

\begin{tabular}{|c|c|c|c|c|c|c|}
\hline \multirow{2}{*}{$\frac{\text { Precipitation }}{\text { Parameters }}$} & & \multicolumn{5}{|l|}{ Test groups } \\
\hline & & All Taxa (54) & Aquatic (63) & Dung (46) & Forest (32) & Riparian (14) \\
\hline \multirow[t]{3}{*}{ Pmap } & CC Poly/Lin & $0.80 / 0 / 80$ & $0.50 / 0.46$ & $0.85 / 0 / 79$ & $0.45 / 0.42$ & $0.85 / 0.60$ \\
\hline & $\mathrm{SDD}(\mathrm{mm})$ & 252 & 421 & 233 & 331 & 249 \\
\hline & Sites in range (\%) & 100 & 98.4 & 100 & 96.9 & 100 \\
\hline \multirow[t]{3}{*}{ PwetM } & CC Poly/Lin & $0.80 / 0 / 80$ & $0.46 / 0.44$ & $0.88 / 0.88$ & $0.38 / 0.37$ & $0.84 / 0.80$ \\
\hline & $\mathrm{SDD}(\mathrm{mm})$ & 45 & 84 & 38 & 44 & 47 \\
\hline & Sites in range (\%) & 96.3 & 93.7 & 100 & 96.9 & 100 \\
\hline \multirow[t]{3}{*}{ PdryM } & CC Poly/Lin & $0.92 / 0.92$ & $0.74 / 0.73$ & $0.90 / 0.87$ & $0.55 / 0.42$ & $0.93 / 0.92$ \\
\hline & $\mathrm{SDD}(\mathrm{mm})$ & 9 & 17 & 11 & 13 & 6 \\
\hline & Sites in range (\%) & 94.4 & 95.2 & 95.7 & 96.9 & 100 \\
\hline \multirow[t]{3}{*}{ PwarmQ } & CC Poly/Lin & $0.80 / 0.78$ & $0.69 / 0.65$ & $0.82 / 0.80$ & $0.80 / 0.74$ & $0.91 / 0.91$ \\
\hline & $\mathrm{SDD}(\mathrm{mm})$ & 97 & 132 & 116 & 71 & 74 \\
\hline & Sites in range (\%) & 100 & 100 & 100 & 100 & 100 \\
\hline \multirow[t]{3}{*}{ PcoldQ } & CC Poly/Lin & $0.91 / 0.91$ & $0.80 / 0.76$ & $0.91 / 0.91$ & $0.63 / 0.60$ & $\mathbf{0 . 9 5} / 0.70$ \\
\hline & $\mathrm{SDD}(\mathrm{mm})$ & 58 & 101 & 46 & 114 & 80 \\
\hline & Sites in range $(\%)$ & 96.3 & 96.8 & 100 & 100 & 100 \\
\hline
\end{tabular}

and North America (Atkinson et al., 1986, 1987; Elias, 1994; Moine et al., 2002). Most frequently, MCR is used to construct twodimensional bioclimatic envelopes (species climatic ranges - SCR) using the parameters TMAX (mean temperature of the warmest month) and TRANGE (difference between mean temperature of the warmest and coldest months). The overlap of the SCR for taxa in a fossil assemblage represents the mutual climatic range and best estimate of summer warmth and annual seasonality.

The MCR approach has several potential limitations in the Australian context, especially the lack of modern data points relative to better collected regions and subsequent difficulty of inferring estimated ranges in two-dimensional climate space (Porch and Elias, 2000). This is equally true of other regions with similarly poorly known modern faunas. As Marra et al. (2004) noted, in reference to New Zealand, the lack of significance of thermal seasonality (something clearly revealed in the modern test data in this paper) limits the utility of the traditional implementation of MCR. To date there has been no published examination of the intercept of climate space with the species climatic ranges contributing to MCR estimates, meaning the contribution of climate space artefacts to climatic parameter estimation in MCR is unknown.

Marra et al. (2004) developed the MLE (maximum likelihood envelope) approach to overcome some of the limitations of MCR, noted above. The method described here is similar to the MLE approach but differs in several relatively minor ways. First, in MLE elevation is derived from digital elevation model data rather that individually geocoded from label or topographic maps. Second, MLE uses a sine model to fit maximum likelihood estimates to the upper and lower bounds of a parameter for each taxon, whereas the method presented here is based on the relationship between sampling density and data quality for a range of increasingly wellsampled taxa. Third, the value of the MLE approach remains unexplored by jack-knifed tests in modern climate space, meaning it is impossible to assess the efficacy of the method, especially given that the number of specimen records contributing to the MLE estimates is never published. Burge and Schulmeister (2007) used MLE to reconstruct precipitation without consideration of the strong positive skew of precipitation profiles relative to those for temperature. Although the approach described here is limited, similarly, by this issue it is explicitly recognised that maximum precipitation estimates need to be interpreted with caution. Future research should compare the value of a range of alternative beetle-based palaeoclimatic reconstruction methods in order to better facilitate meaningful comparison to their results.

\subsubsection{Environmental space limitations}

A potentially major limitation of the quantitative reconstruction of Quaternary climates, noted above, is related to the intersection of the bioclimatic envelopes of taxa and environmental space, specifically, in this case, climatic space. Under the present arrangement of land, climate systems, and environments, the bioclimatic envelopes of taxa necessarily fall within the range of values expressed in the modern climate space- they are derived from this range of values. In the past, and under potential future climate regimes, the range of values certainly has, and will, exceed the range of present values.

In terms of reconstructing past climates this fact introduces a potentially intractable limitation. For example, strongly continental climates are limited to the interior of Australia, a region that today is semi-arid to arid. Increased continentality during glacial periods resulting from lowered sea-levels and generally colder southern oceans (Barrows and Juggins, 2005), means that mesic southeastern Australian regions were, presumably, relatively more continental than they are today (e.g. Kirkpatrick and Fowler, 1998). In modern Australia, the complete absence of mesic beetles in thermally continental environments means all reconstructions based on fossil beetle assemblages that are dominated by (or even include), mesic taxa must, by modern association, be reconstructed as having a moderately equable or maritime thermal regime. Thus, palaeoclimatic reconstruction methods that utilise modern bioclimatic profiles, or indeed the relationship of modern assemblage composition to modern climate, will always be limited to reconstructing the modern climate space relationships. Statistical techniques, like transfer functions, that rely on this relationship can estimate values outside the bounds of the modern dataset, but the value of such predictions is likely to be extremely limited.

A related problem, essentially the reverse of that described above, is similarly limiting. This is the rarity of some climatic regimes in geographical space. Such localities, where the rarity of climate regime may be related to elevation or insularity, for example, are often unlikely to contribute significantly, or at all, to modern datasets that describe the distribution of taxa or assemblages. Thus, if a fossil assemblage is derived from one of these localities, and there are no modern assemblage data from similar climatic regimes in the modern dataset, the reconstructed climate will reflect the most similar sites at which there is modern data, rather than the values for this site itself. This issue is likely to be particularly acute on islands and on climatic islands, like mountain tops, where the modern climate space is geographically, and therefore climatically, limited. 

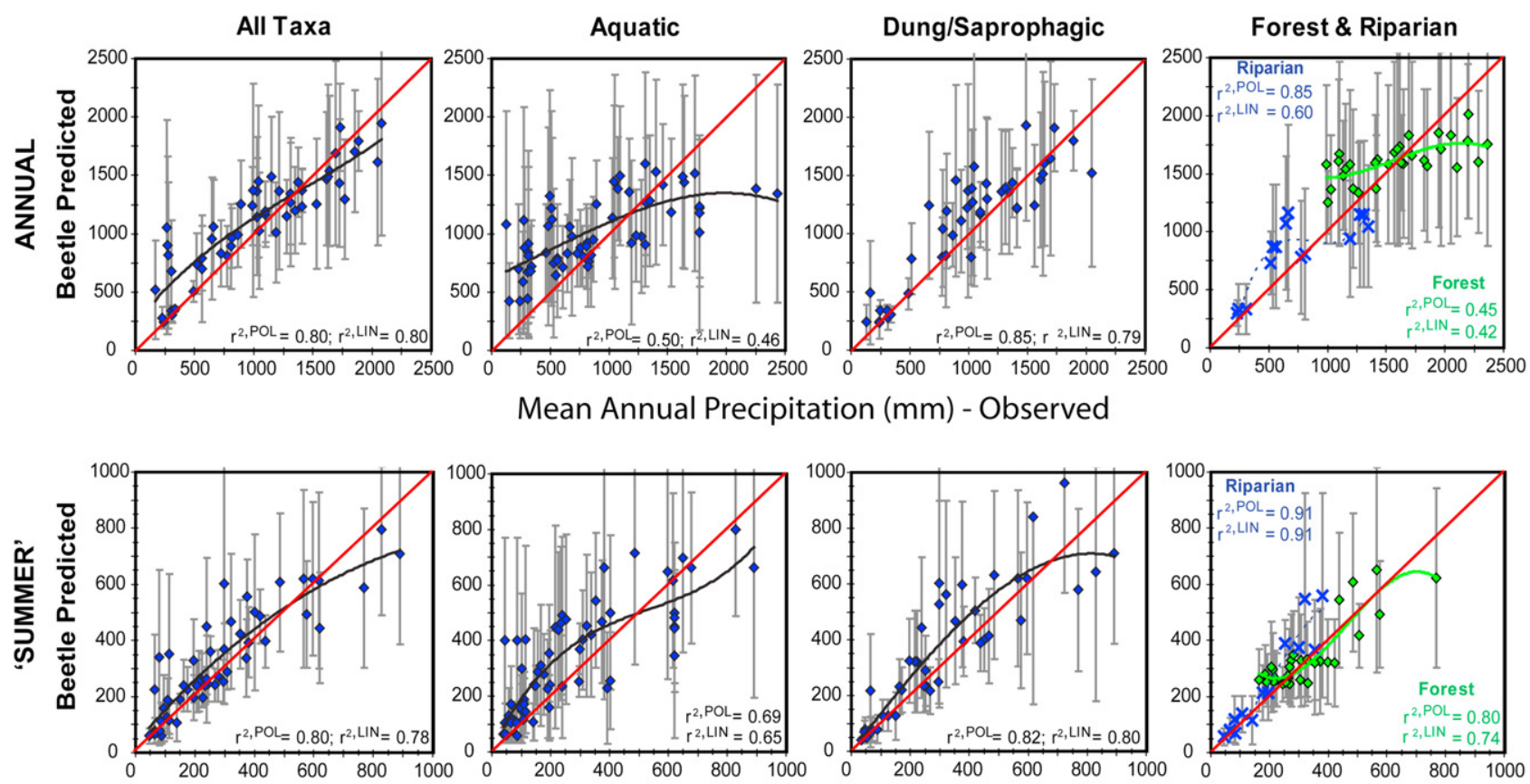

Precipitation of the Warmest Quarter $(\mathrm{mm})$ - Observed
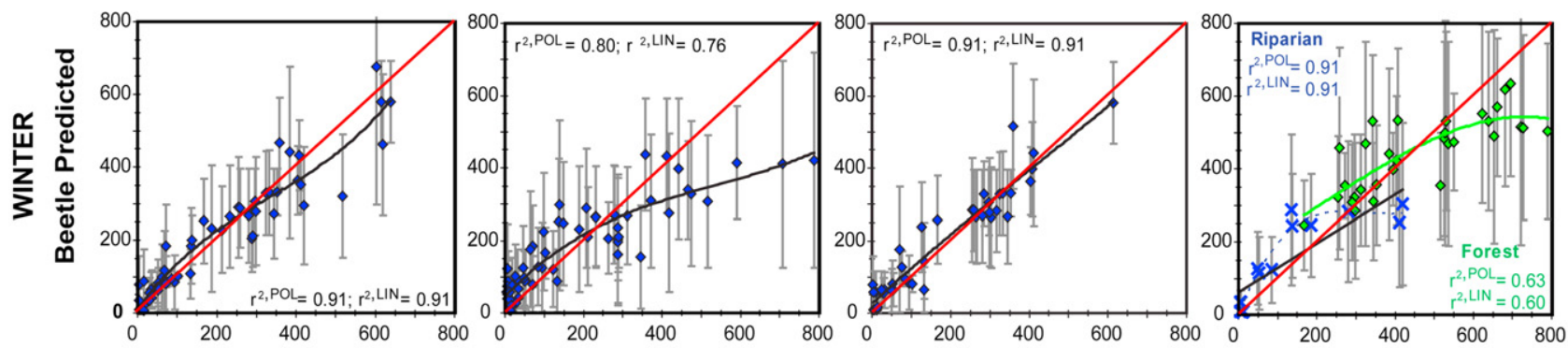

Precipitation of the Coldest Quarter ( $\mathrm{mm}$ ) - Observed
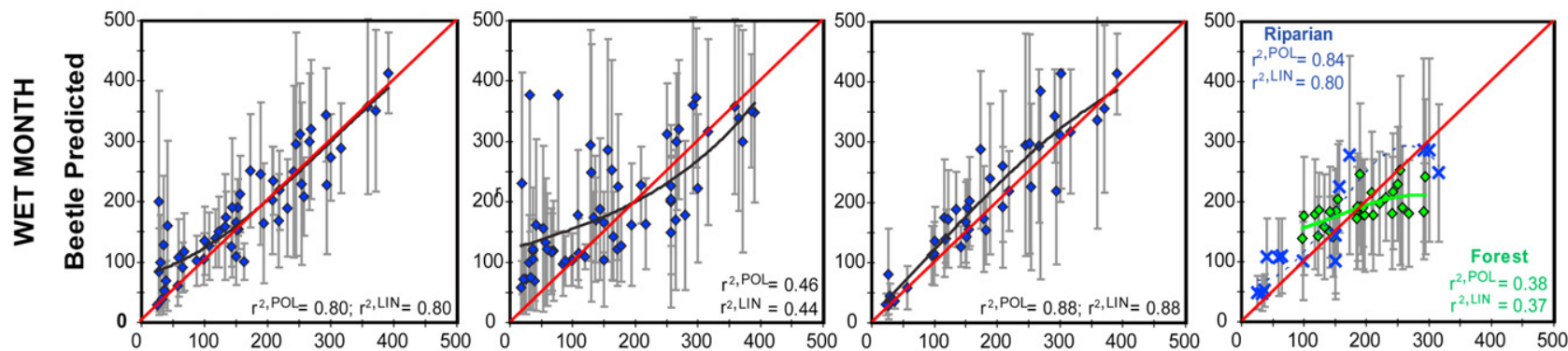

Precipitation of the Wettest Month (mm) - Observed
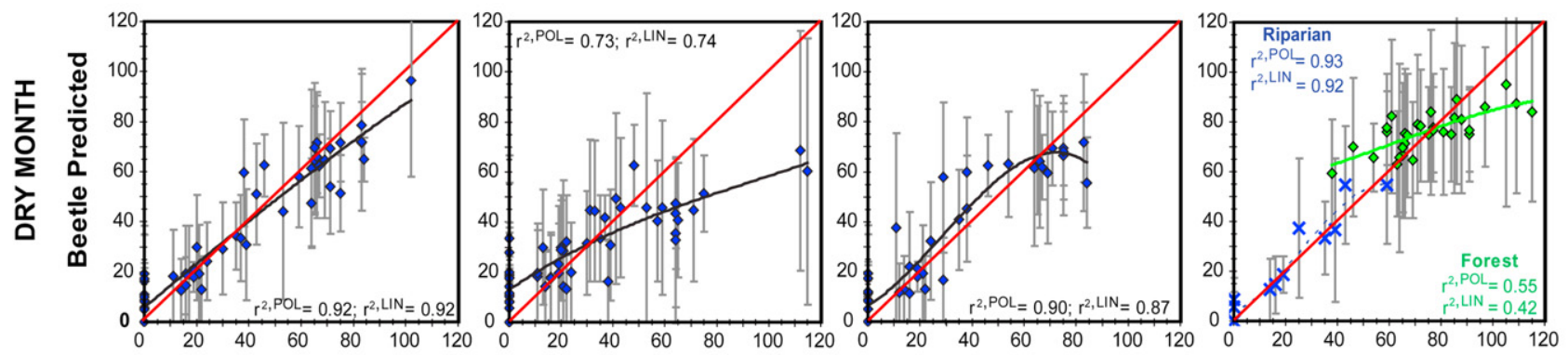

Precipitation of the Driest Month (mm) - Observed

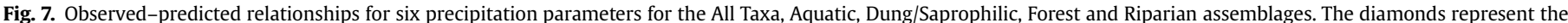

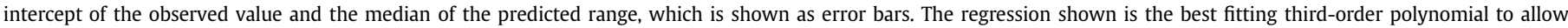
assessment of edge effects (see text). 
The coexistence method, using fossil beetles, can be successfully used for palaeoclimatic reconstruction in Australia, provided a number of issues are carefully considered. Perhaps the most critical consideration is the limitation of past climate spaces that include significantly colder winter climates than exist in the Australian region today. The modern tests presented and discussed in this article show that the winter parameters (TminM, TcoldQ) and annual parameters (MAT, Trange) are reconstructable with high levels of precision and accuracy in modern climate space. It is potentially unwise to assume that this would be the case under conditions of increased continentality across the region. The limited winter climate space of the Australian region means that the increased seasonality of climates that has been suggested by Miller et al. (1997) as characterising the Last Glacial, for example, are not able to be reconstructed. Consequently, a prediction that winter climates were similar to modern can mean two things: the winter climate was the same as modern climate or, alternatively, it was potentially colder, possibly markedly so. This limitation is not restricted to beetle-based methods; indeed, it is a rarely recognised problem of Southern Hemisphere Quaternary palaeoclimatology. The extensive land cover extending into arctic regions means this issue is less significant in the Northern Hemisphere.

Precipitation reconstructions are not subject to the same climate space limitations of many temperature parameters when Quaternary records are sited in lowland southeastern Australia; this region spans the gradient from dominantly winter, to dominantly summer precipitation regimes. Nonetheless, there are still issues that need to be considered when using bioclimatic niche data and coexistence methods to reconstruct past precipitation regimes. Paramount is the recognition that some taxa are likely to be better indicators of precipitation regimes and others are likely to be uninformative. This consideration is reflected in the decision to assess the utility of ecological categories for prediction of temperature and precipitation. It is also necessary to consider that narrow envelopes for precipitation values can simply result from a narrow temperature response (stenotopic species) and the subsequent relationships of the precipitation values in climate space. In such a case, precipitation may not be limiting the taxon at all. For this reason it is critical to assess the utility of individual taxa in Quaternary assemblages, based on the distribution and ecological characteristics, in relation to their contribution to precipitation reconstructions.

\section{Conclusion}

The development of coexistence methods for the reconstruction of past climates using the bioclimatic envelopes of beetles is a potentially powerful approach to the problem of quantitative palaeoclimate reconstruction in Australia. Palaeoclimatic interpretation of Quaternary beetle records will allow comparison of snapshots and short sequences of Quaternary climate with the more continuous pollen record of the region. The relative rarity of accessible organic sequences in Australia means it is less likely that beetle-based palaeoclimatic reconstructions will be developed for extended Quaternary sequences. Nonetheless the ability to compare beetle-derived precipitation and temperature values with quantitative reconstructions based on other proxies, like pollen, will allow critical consideration of the value of individual reconstructions derived from a range of proxies and approaches. Providing that careful consideration of the influence of climate space is included in the interpretation of beetle-based results, beetles will contribute to the resolution of a range of critical questions regarding the climates of Australia during the Quaternary.

\section{Acknowledgements}

A significant part of the research reported here was undertaken while the author was a PhD student in the School of Geography and Environmental Science, Monash University under the supervision of Prof. Peter Kershaw. The support of a Fulbright Postgraduate Student award enabled a year with Scott Elias in the Institute of Arctic and Alpine Research at the University of Colorado during the initial stages of the PhD project. Museum and collection access was facilitated by Tom Weir (Australian National Insect Collection, Canberra), Jan Forrest (South Australian Museum) and Peter Lillywhite (Museum of Victoria). Chris Watts (South Australian Museum) kindly provided a reference collection of southern Australian Dytiscidae and Hydrophilidae. Margaret Thayer and Al Newton (Field Museum of Natural History, Chicago) generously provided extensive collection data for a range of staphylinoid taxa.

\section{References}

Andersen, A., 1993. Beetle remains as indicators of the climate in the Quaternary. Journal of Biogeography 20, 557-562.

Araújo, M.J., Pearson, R.G., 2005. Equilibrium of species' distributions with climate. Ecography 28, 693-695.

Araújo, M.J., Pearson, R.G., Thuiller, W., Erhard, M., 2005. Validation of speciesclimate impact models under climate change. Global Change Biology 11, 1504-1513.

Atkinson, T.C., Briffa, K.R., Coope, G.R., Joachim, M., Perry, D., 1986. Climatic Calibration of coleopteran data. In: Berglund, B.E. (Ed.), Handbook of Holocene Palaeoecology and Palaeohydrology. John Wiley Sons, New York, pp. 851-858.

Atkinson, T.C., Briffa, K.R., Coope, G.R., 1987. Seasonal temperatures in Britain during the past 22,000 years, reconstructed using beetle remains. Nature 325, 587-592.

AUSLIG., 2000. Geodata Raster 250K Version 1.1. AUSLIG, Canberra.

Banks, W.E., d'Errico, F., Peterson, A.T., Kageyama, M., Colombeau, G., 2008. Reconstructing ecological niches and geographic distributions of caribou (Rangifer tarandus) and red deer (Cervus elaphus) during the Last Glacial Maximum. Quaternary Science Reviews 27, 2568-2575.

Barrows, T.T., Juggins, S., 2005. Sea-surface temperatures around the Australian margin and Indian Ocean during the Last Glacial Maximum. Quaternary Science Reviews 24, 1017-1047.

Bartlein, P.J., 1997. Past environmental changes: characteristic features of Quaternary climate variations. In: Huntley, B., Cramer, W., Morgan, A.V., Prentice, H.C., Allen, J.R.M. (Eds.), Past and Future Rapid Environmental Changes. The Spatial and Evolutionary Responses of Terrestrial Biota. Springer, New York, pp. 11-29.

Beaumont, L., Hughes, L., 2002. Potential changes in the distributions of latitudinally restricted Australian butterflies in response to climate change. Global Change Biology 8, 954-971.

Beaumont, L., Hughes, L., Poulsen, M., 2005. Predicting species distributions: use of climatic parameters in BIOCLIM and its impact on predictions of species' current and future distributions. Ecological Modelling 186, 250-269.

Berry, P.M., Dawson, T.P., Harrison, P.A., Pearson, R.G., 2002. Modelling potential impacts of climate change on the bioclimatic envelope of species in Britain and Ireland. Global Ecology and Biogeography 11, 453-462.

Birks, H.J.B., 2003. Quantitative palaeoenvironmental reconstructions from Holocene biological data. In: Mackay, A., Battarbee, R.W., Birks, H.J.B., Oldfield, F. (Eds.), Global Change in the Holocene. Arnold, London, pp. 107-123.

Burge, P.I., Schulmeister, J., 2007. An MIS 5a to MIS 4 (or early MIS 3) environmental and climatic reconstruction from the northwest South Island, New Zealand, using beetle fossils. Journal of Quaternary Science 22, 501-516.

Busby, J.R., 1986. A bioclimatic analysis of Nothofagus cunninghamii (Hook.) Oerst. in southeastern Australia. Australian Journal of Ecology 11, 1-7.

Byrne, M., Yeates, D., Joseph, L., Kearney, M., Bowler, J., Williams, M.A.J., Cooper, S., Donnellan, S., Keogh, J.S., Leys, R., Melville, J., Murphy, D.J., Porch, N., Wywroll, K.-H., 2008. Birth of a biome: insights into the assembly and maintenance of the Australian arid zone biota. Molecular Ecology 17, 4398-4417.

Cook, E.J., van der Kaars, S., 2006. Development and testing of transfer functions for generating quantitative climatic estimates from Australian pollen data. Journal of Quaternary Science 21, 723-733.

Coope, G.R., 1977. Fossil coleopteran assemblages as sensitive indicators of climatic changes during the Devensian (Last) cold stage. Philosophical Transactions of the Royal Society of London. Series B 280, 313-340.

CRES, 1999. AUS40.DEM. Australian National University, Canberra.

Crisp, M.D., Cook, L.G., Steane, D.A., 2004. Radiation of the Australian flora: what can comparisons of molecular phylogenies across multiple taxa tell us about the evolution of diversity in present-day communities? Philosophical Transactions of the Royal Society of London. Series B 359, 1551-1571. 
Dinnin, M.H., Sadler, J.P., 1999. 10,000 years of change: the Holocene entomofauna of the British Isles. Journal of Quaternary Science 14, 545-562.

Elias, S.A., 1994. Quaternary Beetles and Their Environments. Smithsonian Institution Press, Washington.

Elias, S.A., 1997. The mutual climatic range method of palaeoclimate reconstruction based on insect fossils: new applications and interhemispheric comparisons. Quaternary Science Reviews 16, 1217-1225.

Gaston, K.J., 2003. The Stucture and Dynamics of Goegraphic Ranges. Oxford University Press, Oxford.

Graham, C.H., Moritz, C., Williams, S.E., 2006. Habitat history improves prediction of biodiversity in rainforest fauna. Proceedings of the National Academy of Sciences 103, 632-636.

Guisan, A., Zimmermann, N.E., 2000. Predictive habitat distribution models in ecology. Ecological Modelling 135, 147-186.

Hampe, A., 2004. Bioclimatic models: what they detect and what they hide. Global Ecology and Biogeography 11, 469-471.

Harle, K.J., Kershaw, A.P., Clayton, E. (2004). Patterns of vegetation change in southwest Victoria (Australia) over the last two glacial/interglacial cycles: evidence from Lake Wangoom. Proceedings of the Royal Society of Victoria 116, 105-137.

Hesse, P.P., Humphreys, G.S., Selkirk, P.M., Adamson, D.A., Gore, D.B., Nobes, D.C., Price, D.M., Schwenninger, J.L., Smith, B., Tulau, M., Hemmings, F., 2003. Late Quaternary aeolian dunes on the presently humid Blue Mountains, eastern Australia. Quaternary International 108, 13-32.

Hilbert, D.W., Graham, A., Hopkins, M.S., 2007. Glacial and interglacial refugia within a long-termed rainforest refugium: the Wet Tropics Biogregion of NE Queensland, Australia. Palaeogeography, Palaeoclimatology, Palaeoecology 251, 104-118.

Houlder, D.J., Hutchinson, M.F., Nix, H.A., McMahon, J.P. (2000). Anuclim v. 5.1. Centre for Resource and Environmental Studies, Australian National University, Canberra.

Houlder, D., Hutchinson, M., Nix, H., McMahon, J. (2001). ANUCLIM 5.1. User's Guide. Centre for Resource and Environmental Studies, Canberra.

Hugall, A., Moritz, C., Moussalli, A., Stanisic, J. (2002). Reconciling paleodistribution models and comparative phylogeography in the Wet Tropics rainforest land snail Gnarosophia bellendenkerensis (Brazier 1875). Proceedings of the National Academy of Sciences of the United States of America 99, 6112-6117.

Jackson, S.T., Overpeck, J.T., 2000. Responses of plant populations and communities to environmental changes of the late Quaternary. Paleobiology 26, 194-220.

Jackson, S.T., Williams, J.W., 2004. Modern analogs in Quaternary paleoecology: here today, gone yesterday, gone tomorrow? Annual Review of Earth and Planetary Science 32, 495-537.

Kearney, M., Porter, W.P., 2004. Mapping the fundamental niche: physiology, climate and the distribution of a nocturnal lizard. Ecology 85, 3119-3131.

Kershaw, A.P., 1997. A bioclimatic analysis of Early to Middle Miocene brown coal floras, Latrobe Valley, south-eastern Australia. Australian Journal of Botany 45, 373-387.

Kershaw, A.P., Bulman, D., 1996. A preliminary application of the analogue approach to the interpretation of late Quaternary pollen spectra from southeastern Australia. Quaternary International 33, 61-71.

Kershaw, A.P., Nix, H.A., 1988. Quantitative palaeoclimatic estimates from pollen data using bioclimatic profiles of extant taxa. Journal of Biogeography 15, 589-602.

Kershaw, A.P., Nix, H.A. (1989). The use of bioclimatic envelopes for estimation of quantitative palaeoclimatic values, in: T.H. Donnelly, R.J. Wasson (Eds.), CLIMANZ III, Proceedings of the Symposium, Melbourne, 1987. CSIRO Division of Water Resources, Canberra, pp. 78-85.

Kershaw, A.P., van der Kaars, S., 2007. Pollen records, Late Pleistocene: Australia and New Zealand. In: Elias, S.A. (Ed.), Encyclopedia of Quaternary Science. Elsevier, Amsterdam, pp. 2613-2623.

Kershaw, A.P., Bulman, D.P., Busby, J.R., 1994. An examination of modern pre-European settlement pollen samples from southeastern Australia: assessment of their application to quantitative reconstruction of past vegetation and climate. Review of Palaeobotany and Palynology 82, 83-96.

Kershaw, A.P., Tibby, J., Penny, D., Yezdani, H., Walkley, R., Cook, E., Johnston, R. (2004). Latest Pleistocene and Holocene vegetation and environmental history of the Western Plains of Victoria, Australia. Proceedings of the Royal Society of Victoria 116, 139-161.

Kirkpatrick, J.B., Fowler, M., 1998. Locating likely glacial forest refugia in Tasmania using palynological and ecological information to test alternative climatic models. Biological Conservation 85, 171-182.

Lindenmayer, D.B., Nix, H.A., McMahon, J.P., Hutchinson, M.F., Tanton, M.T., 1991 The conservation of Leadbeater's possum Gymnobelideus leadbeateri (McCoy): a case study of the use of bioclimatic modelling. Journal of Biogeography 18, $371-383$.

Lloyd, P.J., Kershaw, A.P., 1997. Late Quaternary vegetation and early Holocene quantitative climate estimates from Morwell Swamp, Latrobe Valley, southeastern Australia. Australian Journal of Botany 45, 549-563.

Marra, M.J., Smith, E.G.C., Shulmeister, J., Leschen, R., 2004. Late Quaternary climate change in the Awatere Valley, South Island, New Zealand using a sine model with a maximum likelihood envelope on fossil beetle data. Quaternary Science Reviews 23, 1637-1650.
Martínez-Meyer, E., Peterson, A.T., Hargrove, W.W., 2004. Ecological niches as stable distributional constraints on mammal species, with implications of Pleistocene extinctions and climate change projections for biodiversity. Global Ecology and Biogeography 13, 305-314.

McKenzie, G.M., Busby, J.R., 1992. A quantitative estimate of Holocene climate using a bioclimatic profile of Nothofagus cunninghamii (Hook.) Oerst. Journal of Biogeography 19, 531-540.

McKenzie, G.M., Kershaw, A.P., 1997. A vegetation history and quantitative estimate of Holocene climate from Chapple Vale, in the Otway region of Victoria, Australia. Australian Journal of Botany 45, 565-581.

Miller, G.H., Magee, J.W., Jull, A.J.T., 1997. Low-latitude glacial cooling in the Southern Hemisphere from amino-acid racemization in emu eggshells. Nature 385, 241-244.

Moine, O., Rousseau, D.D., Jolly, D., Vianey-Liaud, M., 2002. Paleoclimatic reconstruction using Mutual Climatic Range on terrestrial molluscs. Quaternary Research 57, 162-172.

Mosbrugger, V., Utescher, T., 1997. The coexistence approach - a method for quantitative reconstructions of Tertiary terrestrial palaeoclimate data using plant fossils. Palaeogeography, Palaeoclimatology. Palaeoecology 134, 61-86.

Nielsen, A.B., Odgaard, B.V., 2004. The use of historical analogues for interpreting fossil pollen records. Vegetation History and Archaeobotany 13, 33-43.

Nix, H.A., 1991. Biogeography: pattern and process. In: Nix, H.A., Switzer, M.A. (Eds.), Rainforest Animals. Atlas of Vertebrates Endemic to Australia's Wet Tropics. Australian National Parks and Wildlife Service, Canberra, pp. $11-40$.

Nogués-Bravo, D., Rodríguez, J., Hortal, J., Batra, P., Araújo, M.J., 2008. Climate change, humans, and the extinction of the woolly mammoth. PLOS Biology 6 , 685-692.

Pearson, R.G., Dawson, T.P., 2003. Predicting the impacts of climate change on the distribution of species: are bioclimatic envelope models useful. Global Ecology and Biogeography 12, 361-371.

Pearson, R.G., Dawson, T.P., Liu, C., 2004. Modelling species distributions in Britain: a heirarchical integration of climate and land-cover data. Ecography 27, 285-298.

Pearson, R.G., Raxworthy, C.J., Nakamura, M., Peterson, A.T., 2007. Predicting species distributions from small numbers of occurrence records: a test case using cryptic geckos in Madagascar. Journal of Biogeography 34, 102-117.

Porch, N., 2007. In: Elias, S.A. (Ed.), Encyclopedia of Quaternary Science Beetle records: Late Pleistocene of Australia, Vol. 1. Elsevier, Amsterdam, pp. 179-190.

Porch, N. (2008). Invertebrates in landscape archaeology, in: B. David, J. Thomas (Eds.), Handbook of Landscape Archaeology. World Archaeological Congress, Research Handbook Series. Left Coast Press, pp. 457-467.

Porch, N., Elias, S., 2000. Quaternary Beetles: a review and issues for Australian studies. Australian Journal of Entomology 39, 1-9.

Porch, N., Jordan, G.J., Price, D.M., Barnes, R.W., Macphail, M.K., Pemberton, M. 2009. Last interglacial climates of south-eastern Australia: plant and beetlebased reconstructions from Yarra Creek. Quaternary Science Reviews, King Island, Tasmania. doi:10.1016/j.quascirev.2009.09.023.

Prentice, I.C., 1986. Vegetation response to past climatic variation. Vegetatio 67 131-141.

Pulliam, H.R., 2000. On the relationship between niche and distribution. Ecology Letters 3, 349-361.

Rowe, R.J., 2006. Elevational gradient analyses and the use of historical museum specimens: a cautionary tale. Journal of Biogeography 32, 1883-1897.

Shattuck, S., Fitzsimmons, N., 2002. BioLink, the biodiversity information management system (software and documentation). CSIRO Publishing, Collingwood, Victoria.

Sinka, K.J., Atkinson, T.C., 1999. A mutual climatic range method for reconstructing palaeoclimate from plant remains. Journal of the Geological Society 156, 381-396.

Sniderman, J.M.K., Porch, N., Kershaw, A.P., 2009. Quantitative reconstruction of Early Pleistocene climate in southeastern Australia and implications for atmospheric circulation. Quaternary Science Reviews. doi:10.1016/ j.quascirev.2009.08.006.

Thuiller, W., Lavorel, S., Araújo, M.J., 2005. Niche properties and geographical extent as predictors of species sensitivity to climate change. Global Ecology and Biogeography 14, 347-357.

Turney, C.S.M., Haberle, S., Fink, D., Kershaw, A.P., Barbetti, M., Barrows, T.T. Black, M., Cohen, T., Correge, T., Hesse, P.P., Hua, Q., Johnston, R., Morgan, V., Moss, P., Nanson, G., Van Ommen, T., Rule, S., Williams, N.J., Zhao, J.X D’Costa, D., Feng, Y.X., Gagan, M., Mooney, S., Xia, Q., 2006a. Integration of icecore, marine and terrestrial records for the Australian Last Glacial Maximum and Termination: a contribution from the OZ INTIMATE group. Journal of Quaternary Science 21, 751-761.

Turney, C.S.M., Kershaw, A.P., Lowe, J.J., van der Kaars, S., Johnston, R., Rule, S., Moss, P., Radke, L., Tibby, J., McGlone, M.S., Wilmshurst, J.M., Vandergoes, M.J., Fitzsimons, S.J., Bryant, C., James, S., Branch, N.P., Cowley, J., Kalin, R.M., Ogle, N. Jacobsen, G., Fifield, L.K., 2006b. Climatic variability in the southwest Pacific during the Last Termination (20-10 kyr BP). Quaternary Science Reviews 25, 886-903.

van der Kaars, S., De Deckker, P., Gingele, F.X., 2006. A 100,000-year record of annual and seasonal rainfall and temperature for northwestern Australia 
based on a pollen record obtained offshore. Journal of Quaternary Science 21, 879-889.

Whitehouse, N.J., 2006. The Holocene British and Irish ancient forest fossil beetle fauna: implications for forest history, biodiversity and faunal colonisation. Quaternary Science Reviews 25, 1755-1789.

Williams, S.E., 1998. Spatial patterns of vertebrate biodiversity and assemblage structure in the rainforest of the Australian Wet Tropics. Australian Journal of Ecology 23, 185-186.
Williams, S.E., Bolitho, E.E., Fox, S. (2003). Climate change in Australian tropical rainforests: an impending environmental catastrophe. Proceedings of the Royal Society of London B 270, 1887-1892.

Williams, M., Cook, E., van der Kaars, S., Barrows, T., Shulmeister, J., Kershaw, P., 2009. Glacial and deglacial climatic patterns in Australia and surrounding regions from 35000 to 10000 years ago reconstructed from terrestrial and near-shore proxy data. Quaternary Science Reviews 28, 2398-2419. 